\title{
Article \\ GIS Mapping of Short-Term Noisy Event of Diwali Night in Lucknow City
}

\author{
Rakesh Dubey ${ }^{1,+}$, Shruti Bharadwaj ${ }^{1,+}\left(\mathbb{D}\right.$, Md Iltaf Zafar ${ }^{1,+}$, Vanshu Mahajan ${ }^{2}$, Anubhava Srivastava ${ }^{1}$ \\ and Susham Biswas $1, *$ (D)
}

check for updates

Citation: Dubey, R.; Bharadwaj, S.; Zafar, M.I.; Mahajan, V.; Srivastava,

A.; Biswas, S. GIS Mapping of Short-Term Noisy Event of Diwali Night in Lucknow City. ISPRS Int. J Geo-Inf. 2022, 11, 25. https:// doi.org/10.3390/ijgi11010025

Academic Editor: Wolfgang Kainz

Received: 23 October 2021

Accepted: 26 December 2021

Published: 30 December 2021

Publisher's Note: MDPI stays neutral with regard to jurisdictional claims in published maps and institutional affiliations.

Copyright: (C) 2021 by the authors. Licensee MDPI, Basel, Switzerland. This article is an open access article distributed under the terms and conditions of the Creative Commons Attribution (CC BY) license (https:// creativecommons.org/licenses/by/ $4.0 /)$
1 Surveying Lab, Department of Computer Science and Engineering and Engineering Science, Rajiv Gandhi Institute of Petroleum Technology, Amethi 229304, India; pgi19001@rgipt.ac.in (R.D.); pgi17001@rgipt.ac.in (S.B.); pgi15001@rgipt.ac.in (M.I.Z.); pgi18001@rgipt.ac.in (A.S.)

2 Department of Chemical Engineering and Engineering Science, Rajiv Gandhi Institute of Petroleum Technology, Amethi 229304, India; Eche17057@rgipt.ac.in

* Correspondence: susham@rgipt.ac.in; Tel.: +91-6388415537

+ These authors contributed equally to this work.

\begin{abstract}
Noise is a universal problem that is particularly prominent in developing nations like India. Short-term noise-sensitive events like New Year's Eve, derby matches, DJ night, Diwali night (celebration with firecracker) in India, etc. create lots of noise in a short period. There is a need to come up with a system that can predict the noise level for an area for a short period indicating its detailed variations. GIS (Geographic Information System)-based google maps for terrain data and crowd-sourced or indirect collection of noise data can overcome this challenge to a great extent Authors have tried to map the highly noisy Diwali night for Lucknow, a northern city of India. The mapping was done by collecting the data from 100 points using the noise capture app $30 \%$ were close to the source and 70\% were away from the source (receiver). Noise data were predicted for 750 data points using the modeling interpolation technique. A noise map is generated for this Diwali night using the crowd-sourcing technique for Diwali night. The results were also varied with 50 test points and are found to be within $\pm 4.4 \mathrm{~dB}$. Further, a noise map is also developed for the same site using indirect data of noise produced from the air pollution open-sourced data. The produced noise map is also verified with 50 test points and found to be $\pm 6.2 \mathrm{~dB}$. The results are also corroborated with the health assessment survey report of the residents of nearby areas.
\end{abstract}

Keywords: GIS; crowdsource technique; noise pollution; short span event mapping; Diwali night; firecracker

\section{Introduction}

With the increase in population, people are moving more towards the prevalent technology, however various health implications are associated with such modern technologies. For example, modernization has enhanced noise levels and this causes some severe health issues. The land-use pattern in developing countries puts an adverse effect on health due to mixed land-use patterns and unorganized terrain parameters [1]. This will not provide proper passage for the noise to propagate which leads to frequent noise impacts at a location. The annoyances in the city environment are affecting health significantly [2]. The health implications like tinnitus, sleep disturbances, high BP are more prominent in people residing near the crossing having more exposure to road noise [3]. The necessity to measure the levels of noise pollution in an area is increasing day by day and thus, various models are being derived by the researchers to showcase the relationship between the health implications and noise exposure with the help of confidence interval [4]. Many pieces of evidence associate traffic noise with ischemic diseases or cardiovascular diseases, associations with blood pressure have been inconsistent about health effects of railway noise [5,6]. In special cases like the festive event, celebrations, marriages where the firecrackers are used leads 
to short span noise-sensitive events and it also has various health implications associated with it same as due to road noise [7]. One of the main objectives that have to be derived is to propose a model to avoid the causes like sleep disturbances among people of old age [8]. Major strategies that must be developed to tackle such issues necessitate accurate monitoring and analysis of noise sources and determining the propagation of noises to surrounding locations. The varied noise levels may be easily predicted using various empirical or semi-empirical models. The prediction of noise requires terrain data, noise data, and a prediction model. The terrain data dependency for noise modeling can be done through direct and indirect capturing with the camera, UAV systems, etc. [9]. Monitoring of the noise is also difficult due to its transient nature and with better accuracy requires expensive Sound level meter-SPL. Smartphone-based noise capturing is a solution but the inaccuracy of data collection is a problem [10]. However, the challenge of the collection of data for a large number of points can be resolved through prediction [11]. An indirect method of retrieving the noise data from air pollution can be thought of for this SNSE. Efficient crowd-sourcing over the web offers a wide range of possibilities for exploring monitored data to map noise levels in different cities [12]. The authors have tried to monitor and map the SNSE using the smartphone-based technique. The publishing of the map and showcasing the deterioration in noise level is also a need [13]. The GIS-based mapping provides numerically simulated data through software programs that are primarily advanced for ambient noise mapping activities. It employs acoustic principles derived from one-of-a-kind resources [14]. With the information provided above, the authors are conducting surveillance in the city of Lucknow. A cohesive investigation was conducted within the West-Bengal metropolis in which the time series and spatial noise distribution of traffic noise over the street and nearby buildings were acquired using the SPL and plotted on a web platform using the GIS [15]. On the other hand, in Nigeria's metropolitan areas, the same data became recorded and stimulated on the GIS platform. On the GIS platform, IDW interpolations were generated for the map, and one inspired variation became a set consistent with the WHO well-known for the annoyances with the use of spatial interpolation [16]. Aside from that, a few people have employed questionnaire surveys to assess a location's noise level. However, the polling results are limited to a specific sector and the inability to remember [17]. They provided a completely average sense of noise for the area and its incapacity to remember the terrain parameters [18], and different occasions over the period and location. The primary goal of the web-based GIS platform is to provide an accessible platform to generate the map and be easily viewable over the web platform with the user's assistance. With the help of the GIS platform connecting with the web, various types of statistical or terrain parameters can be uploaded, with assistance to spatial reference, mapped, and can be easily accessed and tracked for data sharing [19]. It includes a collection of web-based services that deliver information and capabilities to networked software programmed customers [20]. GIS-based web platform serves as a platform for integration, encourages cross-organizational communication, and allows for better decisionmaking [21]. In the case of web mapping basically, the data collected and mapped is to be stimulated over the web platform so that it can be seen by different users around the world. In the case of the web mapping technique, users around the organization of the world can collect the data and upload it on the same web platform [22]. The flow chart shows the crowd-sourced collaborative mapping of noise data which can be published and can be seen by different users. The usage of Arc Info or ArcView software provided through a license enables the user to modify and convert the view to examine the data in the required format [23]. The processing of the raster image through GIS while extracting the building roads etc. to generate the vector map [24]. This web-based interactive server exposes users to a variety of websites by providing links to interactive GIS mapping and GIS data downloads [10].

Researchers have utilized various models effectively to determine the noise data and to create noise maps. This modeling can be carried out using the following two techniques:

- Interpolation based noise prediction 
- Acoustic modeling-based noise prediction

Interpolation is a method of generating a sample from values at distant pattern variables. Sample variables are locations where we collect data on a phenomenon and store the spatial coordinates. The noise prediction model is one of the most important techniques necessary for decision for reducing the negative effects of noise and controlling it [25].

\subsection{Noise Modeling and Its Data Dependency}

Noise modeling primarily depends on terrain data and noise data, further [26], the noise data can be managed by direct technique (crowd-sourced based noise data collection) and indirect technique of noise data collection. Terrain and noise data dependency are important.

- $\quad$ Noise data dependency:

- Direct method of noise data collection for noise mapping (using crowd-sourced noise data)

- Indirect method of noise modeling with air quality data.

The crowd-sourced noise mapping technique is the one in which noise data are collected by the users and sent to the web. The web platform stores the data within the same interface where the user is uploading the data from different sources. These are also time series data and in real-time they should be corrected before uploading it on the web. Upgrading and uploading the data requires reviewing of data. Crowd-sourcing is a methodology that emphasizes the pattern of correcting data that have been uploaded by reviewing and stimulating it to a specific range (Figure 1).

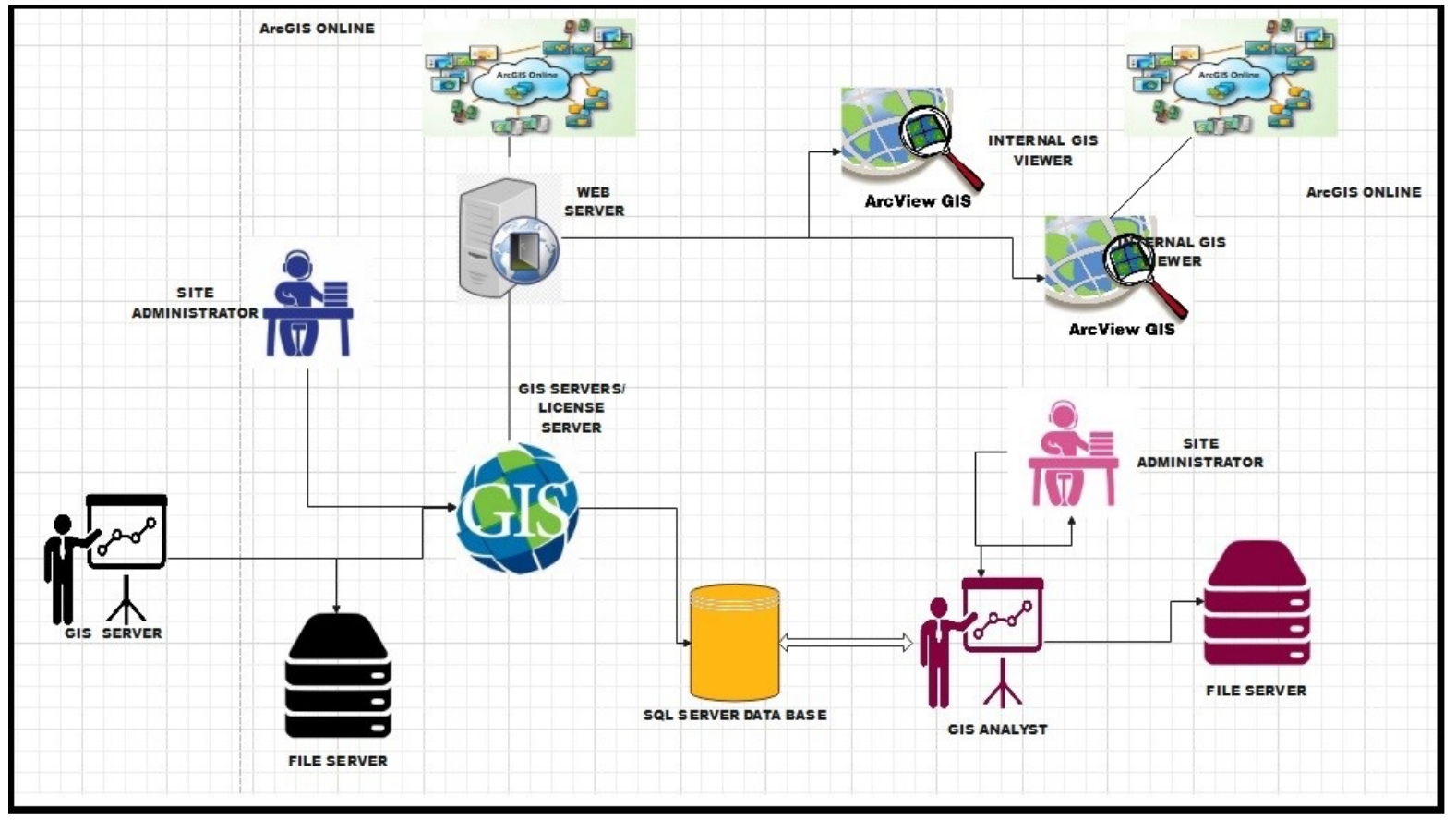

Figure 1. The figure showing the crowd-sourcing the data collection and mapping it on the web platform.

\subsection{Indirect Method of Noise Modeling with Air Quality Data}

Venkata et al. (2013) has investigated and performed experiments to get the variational changes in characteristics of aerosol, concentration, and radiative particles in the air due to firecrackers on Diwali [27]. The assessment was based on six days of intensive analyses of various contaminants such as black carbon, particulate matter, and aerosol optical depth to capture the drastic variation in fireworks from pre-Diwali to post-Diwali. There has 
also been a major increase in gaseous air emissions such as $\mathrm{SO}_{2}$ and $\mathrm{NO}_{\mathrm{x}}$ levels that meet National Ambient Air Quality Standards [28]. Such celebration-induced air pollution events can have major health repercussions, particularly for the respiratory and cardiovascular illnesses of the local population [3]. Ambient air pollution is one of the most serious environmental health hazards. This is becoming more prevalent by the day and has a significant impact on human health. According to a 2017 survey, exposure to $\mathrm{PM}_{2.5}$ was responsible for over 3 million fatalities worldwide. The use of fireworks at these activities produces smoke plumes, which can temporarily increase PM concentrations. The impact of using fireworks (and bonfires) has a negative effect on air quality, illumination, and human health. There is a lot of evidence showing that these events contain a lot of toxins, and as a result, there may be a lot of multipollutant radiation [29]. Pollutant concentrations (such as $\mathrm{PM}_{2.5}, \mathrm{PM}_{10}$, and $\mathrm{NO}_{\mathrm{x}}$ ) increase more noticeably before and shortly after the fireworks display, followed by a return to baseline values, usually within $24 \mathrm{~h}$. During fireworks show, peak pollutant concentrations can be $2-8$ times higher than ambient levels. Thus the authors provide a list of potential research targets to better understand the effects of fireworks and bonfires on human and environmental health [30].

In the case of noise mapping, we primarily are required to incorporate the terrain data and noise data. The noise data of different sources are integrated and then terrain and noise data are incorporated in the noise propagation model to predict the level of noise at the desired location. By developing a noise propagation model, we can make noise predictions for even those locations where we do not have any noise data. The predictions can be displayed as a noise map. The authors here have tried to do the same in this article. In this article, the authors have proposed a novel technique to predict the levels of noise even in short-term noise events like Diwali, wherein it is very difficult to collect relevant noise data. So, to solve this issue, the authors have tried to collect noise data indirectly using air quality. During Diwali night, noise levels and pollutants in the air increase in the same proportion. Therefore, by measuring the air pollutants level, the noise data can be collected and these data can be used to predict the levels of noise in a particular area.

\section{Research Gap}

Noise mapping necessitates precise noise data. Noise maps can be developed using a GIS platform that computes noise data over a broad area. Earlier the researchers were using the primitive technique of data collection using the costly sound pressure level meter that requires time and extra care due to its sensitivity and cost.

Authors understand that data collection is required to be carried out at strategic locations. In the case of Diwali night, for which SNSE requires extensive data collection within a very short period during the event. For Diwali night, this may be achieved through crowd-sourced techniques. It requires precise instruments and a lot of logistic support.

The above task is difficult, it requires detailed monitoring at every location of the event. So, there is a need for an alternative technique using open-sourced indirect data. Literature suggests that deterioration of noise quality is highly correlated with air quality [15]. Thus, it is required to find out the relationship between change in noise level vis a vis change in air quality parameters for the SNSE (Diwali).

The authors will try to find the technique that can measure the extent of noise pollution in the city of LUCKNOW for SNSE like Diwali night. The noise maps are crowd-sourced considering the involvement of the general public for collaborative mapping by collecting the data at their respective source locations. Whenever the crowd-sourced technique is not possible, the alternative indirect data collection technique may be applied.

1. SNSE-Noise mapping using Crowd-sourced Noise data: noise data for SNSE like Diwali Night in Lucknow city is required to be collected through crowdsourced based noise collection technique. A low-cost, convenient, SBNC app can be used for data collection, which can be calibrated before mapping. Crowd-sourced data with the support of open-sourced terrain data (google earth images) would predict noise levels at different locations. 
2. Using the indirect open-sourced noise data for SNSE noise mapping: Whenever the crowd-sourced technique is not practical to offer the noise data, an alternative noise collection technique is required to be determined. Noise levels change significantly during Diwali night, so do the air quality parameters with the bursting of firecrackers. A relationship between the change in air quality vis a vis to that of noise quality during SNSE is required to be established. The records of a significant rise in air quality parameters during SNSE-Diwali along with noise levels give the clue for determining the relationship. Once it is established it can be applied to estimate noise map for Diwali night using change in air quality data.

Prediction of noise maps for SNSE-Diwali nights-is also required to be verified with the field data and the adverse health impacts experienced by residents residing near the events.

\section{Methodology}

The main objective of the study is to map the SNSE like Diwali night, new year eve's, derby match, DJ night, etc. The authors chose Diwali night for the SNSE mapping.

Site selection comprises choosing Lucknow, a northern Indian city for mapping SNSE during Diwali. In order to develop the noise map, three basic components, namely noise data, terrain data, and noise model are required. Data collection comprises direct source noise data collection and indirect source noise data collection (whenever direct noise data collection is not possible). The direct noise data were collected 1 meter above the ground.

The main importance is given to the collection of noise data for the Short-Term Noise Event (SNSE). Noise data were collected through crowd-sourced techniques from the site of Haniman Crossing in Lucknow city. The noise data of 40 source points (near the bursting of firecrackers) and 760 receiver points were recorded using Smartphone NC (Smart Phone-Based Noise Level Capturing App). The collected noise data are calibrated with a standard SPL meter in an anechoic chamber before introducing inside the noise prediction model. The terrain data can easily be acquired from open-sourced Google Earth images. The authors used their terrain data extraction algorithm from the GIS platform, which is explained in their previous work (Figure 2).

The indirect noise data collection was carried out after observing the change in air quality parameters. The changes for the Diwali nights and other nights were observed in relation to noise level data to establish a relationship. The indirect data of air quality vs. noise quality are acquired from the IITR (Indian Institute of Toxicological Research) report for 9 locations for the year 2019 in Lucknow city.

The noise modeling is being performed using the modeling-cum-interpolation technique. The mapping for special occasions like Diwali is performed using noise data that has been measured with the help of crowdsourcing. With the help of the Smartphone NC app, the data were collected at Haniman chauraha and verified. In real-world settings, the crowd-sourced approach has drawbacks since individuals are more focused on celebrating the festival than on the collection of the data. So, the indirect source noise data collection was administered.

The direct and indirect techniques for SNSE like Diwali night mapping were verified with 60 test points collected from the ground. The prediction is further corroborated using the health assessment report of the experimenting sites (Figure 3). 


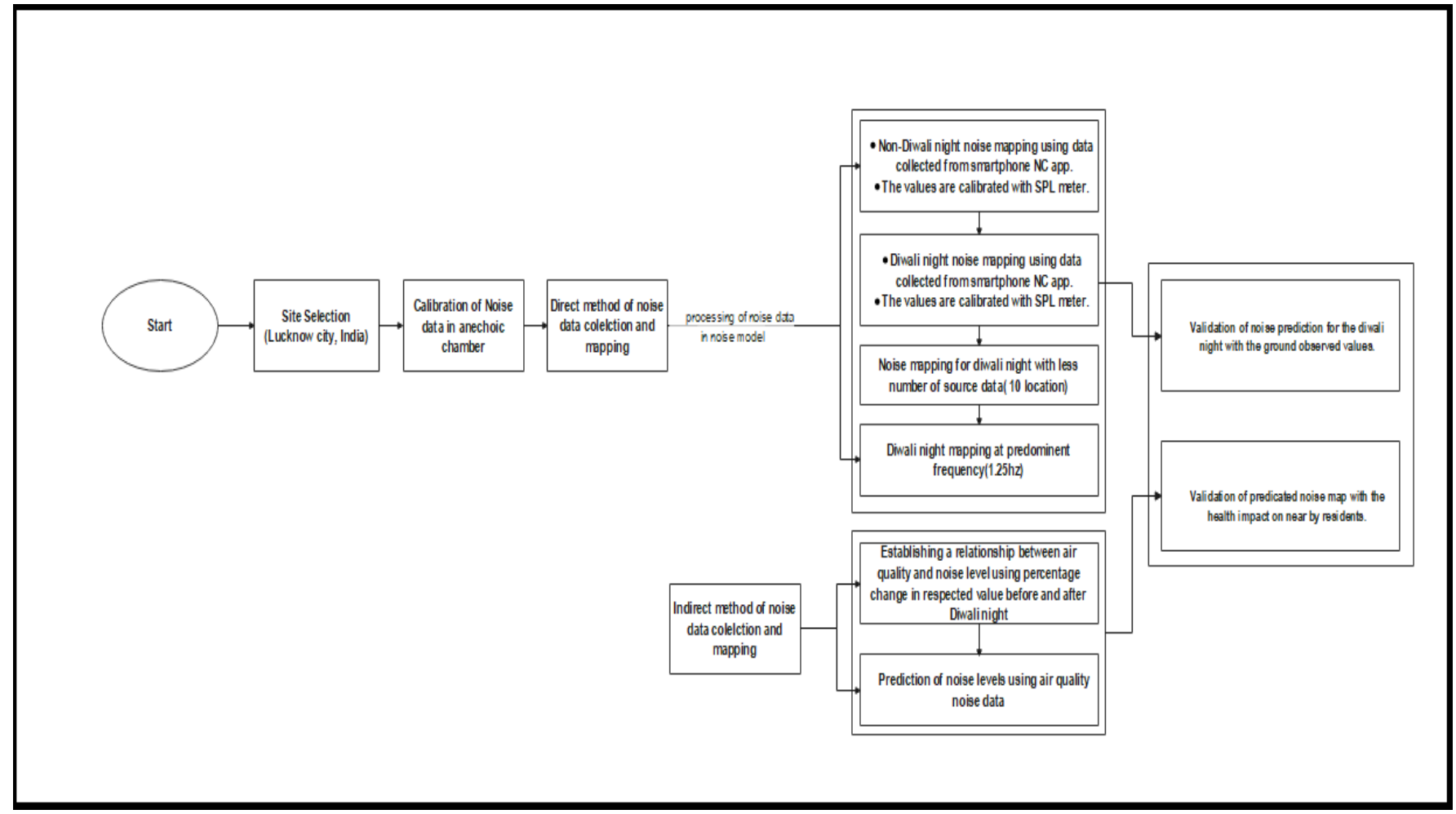

Figure 2. The flowchart shows the methodology used in the study.

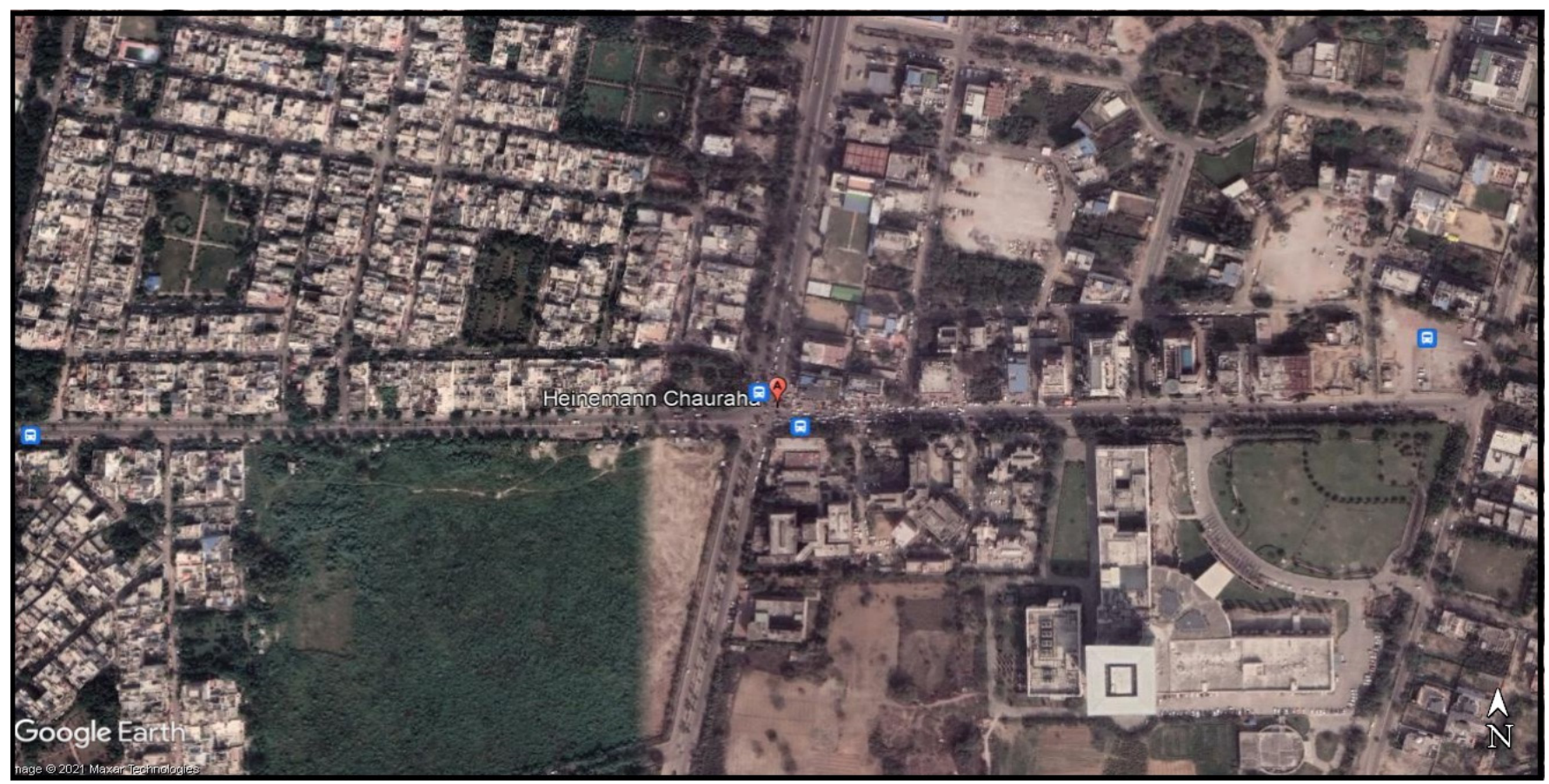

Figure 3. Google image of the experimental site where the noise mapping and health survey is being performed.

\section{Computations for Noise Modeling}

The terrain parameters of different locations were calculated using the distance of a receiver from the noise source, reflection, and diffraction of the direction leading to various losses, and so on (i.e., roads). The computations were used to estimate noise levels, which 
are then shown on a map. The path gap occurs due to the obstacle claimed by different buildings over the exact path difference in noise levels from source to receiver [16]. So, in such cases, barrier attenuation (building) is used. The following are some of the different computations that have been used to calculate the attenuations.

$$
\begin{gathered}
\text { Noise level }(\text { Receiver })=\text { Noise level }(\text { source })-\text { Distance attenuation }- \text { B.A } \\
\text { Distance Attenuation (D.A. })=20 \text { LOG10 }(\mathrm{D})+11 \\
\text { B.A }=5.65+66 \mathrm{~N}+244 \mathrm{~N}^{2}+287 \mathrm{~N}^{3} \\
\mathrm{~N}=\frac{\text { Path difference }}{\frac{\lambda}{2}} \\
\lambda=\frac{\mathrm{c}}{\mathrm{f}} \\
\text { Path Difference }=\mathrm{D} 1-\mathrm{D}
\end{gathered}
$$

where $\mathrm{D}=$ Direct transmission path

D1 = Indirect transmission path

B.A = Barrier attenuation

$\lambda=$ wavelength

$\mathrm{c}=$ Speed of light

$\mathrm{f}=$ Frequency

$\mathrm{N}=$ Fresnel number

D.A. = distance attenuation between source and the receiver

$\mathrm{L} \sum=$ logarithmic summation of all the combinations of the source to a receiver

(Reflection, diffraction)

B.A. = barrier attenuation between source to a receive

$\mathrm{D}=$ direct transmission path between source to the receiver

We have data for eight locations that contain the value of $\mathrm{PM}_{2.5}, \mathrm{SO}_{\mathrm{x}}, \mathrm{NO}_{\mathrm{x}}$, and the $\mathrm{dB}$ value. For the eight different locations, 84 combinations were made. Now we have data of 84 points, out of which 74 are the training set and 10 are testing. Training data are for 74 points out of 84 points where 10 points are for testing purposes.

$$
\mathrm{dB}=\mathrm{a} \times\left(\mathrm{PM}_{2.5}\right)+\mathrm{b} \times\left(\mathrm{SO}_{\mathrm{x}}\right)+\mathrm{c} \times\left(\mathrm{NO}_{\mathrm{x}}\right)
$$

Here $\mathrm{dB}$ value, $\mathrm{PM}_{2.5}, \mathrm{SO}_{\mathrm{x}}, \mathrm{NO}_{\mathrm{x}}$ are known.

$\mathrm{a}, \mathrm{b}, \mathrm{c}$ are unknown factors, like this way we have 74 different locations based on the training dataset.

- $\quad$ For point 1 the Equation is

$$
\mathrm{dB}_{1}=\mathrm{a} \times\left(\mathrm{PM}_{2.5}\right)_{1}+\mathrm{b} \times\left(\mathrm{SO}_{\mathrm{x}}\right)_{1}+\mathrm{c} \times\left(\mathrm{NO}_{\mathrm{x}}\right)_{1}
$$

- Point 2 the Equation is

$$
\mathrm{dB}_{2}=\mathrm{a} \times\left(\mathrm{PM}_{2.5}\right)_{2}+\mathrm{b} \times\left(\mathrm{SO}_{\mathrm{x}}\right)_{2}+\mathrm{c} \times\left(\mathrm{NO}_{\mathrm{x}}\right)_{2}
$$

- $\quad$ Point 3 the Equation is

$$
\mathrm{dB}_{3}=\mathrm{a} \times\left(\mathrm{PM}_{2.5}\right)_{3}+\mathrm{b} \times\left(\mathrm{SO}_{\mathrm{x}}\right)_{3}+\mathrm{c} \times\left(\mathrm{NO}_{\mathrm{x}}\right)_{3}
$$

- Point 74 the Equation is

$$
\mathrm{dB}_{74}=\mathrm{a} \times\left(\mathrm{PM}_{2.5}\right)_{74}+\mathrm{b} \times\left(\mathrm{SO}_{\mathrm{x}}\right)_{74}+\mathrm{c} \times\left(\mathrm{NO}_{\mathrm{x}}\right)_{74}
$$


We can write the above equations as

$$
\begin{aligned}
& Y_{1}=a X_{1}+b L_{1}+c M_{1} \\
& Y_{2}=a X_{2}+b L_{2}+c_{2} \\
& Y_{3}=a X_{3}+b L_{3}+c_{3} \text { and so on. }
\end{aligned}
$$

In order to find the best-fit line, we try to solve the above equations in the unknowns $a, b$, and c. As the 74 points do not lie on a line, there is no actual solution, so instead, we compute a least-squares solution. Putting our linear equation into matrix form.

$$
\text { Computing A.x = b }
$$

$$
\begin{gathered}
\mathrm{A}=\left(\begin{array}{ccc}
\mathrm{X}_{1} & \mathrm{~L}_{1} & \mathrm{M}_{1} \\
\mathrm{X}_{2} & \mathrm{~L}_{2} & \mathrm{M}_{2} \\
\mathrm{X}_{3} & \mathrm{~L}_{3} & \mathrm{M}_{3} \\
\mathrm{M} & \mathrm{M} & \mathrm{M} \\
\mathrm{X}_{74} & \mathrm{~L}_{74} & \mathrm{M}_{74}
\end{array}\right), \mathrm{b}=\left(\begin{array}{c}
\mathrm{Y}_{1} \\
\mathrm{Y}_{2} \\
\mathrm{Y}_{3} \\
\mathrm{M} \\
\mathrm{Y}_{74}
\end{array}\right), \text { and } \mathrm{x}=\left(\begin{array}{c}
\mathrm{a} \\
\mathrm{b} \\
\mathrm{c}
\end{array}\right) \\
\mathrm{A}^{\mathrm{T}} \mathrm{A} \cdot \mathrm{x}=\mathrm{A}^{\mathrm{T}} \cdot \mathrm{b}
\end{gathered}
$$

$$
\mathrm{A}^{\mathrm{T}}=\left(\begin{array}{ccccc}
\mathrm{X}_{1} & \mathrm{X}_{2} & \mathrm{X}_{3} & \mathrm{~L} & \mathrm{X}_{74} \\
\mathrm{~L}_{1} & \mathrm{~L}_{2} & \mathrm{~L}_{3} & \mathrm{~L} & \mathrm{~L}_{74} \\
\mathrm{M}_{1} & \mathrm{M}_{2} & \mathrm{M}_{3} & \mathrm{~L} & \mathrm{M}_{74}
\end{array}\right)
$$

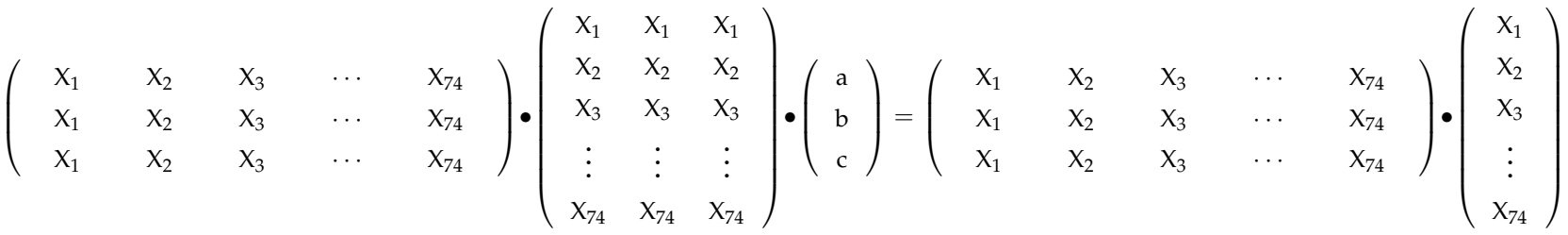

$$
\left(\begin{array}{ccc}
\sum_{i=1}^{74} X_{i}^{2} & \sum_{i=1}^{74} X_{i} \bullet X_{i} & \sum_{i=1}^{74} X_{i} \bullet X_{i} \\
\sum_{i=1}^{74} X_{i} \bullet X_{i} & \sum_{i=1}^{74} X_{i}^{2} & \sum_{i=1}^{74} X_{i} \bullet X_{i} \\
\sum_{i=1}^{74} X_{i} \bullet X_{i} & \sum_{i=1}^{74} X_{i} \bullet X_{i} & \sum_{i=1}^{74} X_{i}^{2}
\end{array}\right) \bullet\left(\begin{array}{l}
a \\
b \\
c
\end{array}\right)=\left(\begin{array}{c}
\sum_{i=1}^{74} X_{i} \bullet X_{i} \\
\sum_{i=1}^{74} X_{i} \bullet X_{i} \\
\sum_{i=1}^{74} X_{i} \bullet X_{i}
\end{array}\right)
$$

$$
\left(\begin{array}{c}
\left(\sum_{i=1}^{74} X_{i}^{2} \bullet a+\left(\sum_{i=1}^{74} X_{i} \bullet X_{i}\right) \bullet b+\left(\sum_{i=1}^{74} X_{i} \bullet X_{i}\right) \bullet c\right. \\
\left(\left(\sum_{i=1}^{74} X_{i} \bullet X_{i}\right) \bullet a+\left(\sum_{i=1}^{74} X_{i}^{2}\right) \bullet b+\left(\sum_{i=1}^{74} X_{i} \bullet X_{i}\right) \bullet c\right. \\
\left(\left(\sum_{i=1}^{74} X_{i} \bullet X_{i}\right) \bullet a+\left(\sum_{i=1}^{74} X_{i} \bullet X_{i}\right) \bullet b+\left(\sum_{i=1}^{74} X_{i}^{2}\right) \bullet c\right.
\end{array}\right)=\left(\begin{array}{c}
\sum_{i=1}^{74} X_{i} \bullet X_{i} \\
\sum_{i=1}^{74} X_{i} \bullet X_{i} \\
\sum_{i=1}^{74} X_{i} \bullet X_{i}
\end{array}\right)
$$

where $\mathrm{X}$ is $\mathrm{PM}_{2.5}, \mathrm{~L}$ is $\mathrm{SO}_{\mathrm{x}}, \mathrm{M}$ is $\mathrm{NO}_{\mathrm{x}}$ and $\mathrm{a}, \mathrm{b}, \mathrm{c}$ are unknowns.

\section{Results and Discussion}

There were issues in the noise mapping of Diwali nights and non-Diwali nights. The authors used the direct method of noise data collection and the indirect method of noise data collection for Diwali and non-Diwali night. The crowd-sourced data collection was calibrated with a standard SPL meter. The experiment was performed in an anechoic chamber. The mapping of non-Diwali night and Diwali night were compared. Indirect noise data collection (air quality-based data) was performed where the crowd-sourced data 
collection failed. In this, a relationship was established between the air quality and noise levels using the respected values before and after Diwali night. The scheme shows the way the study was performed (Figure 4).

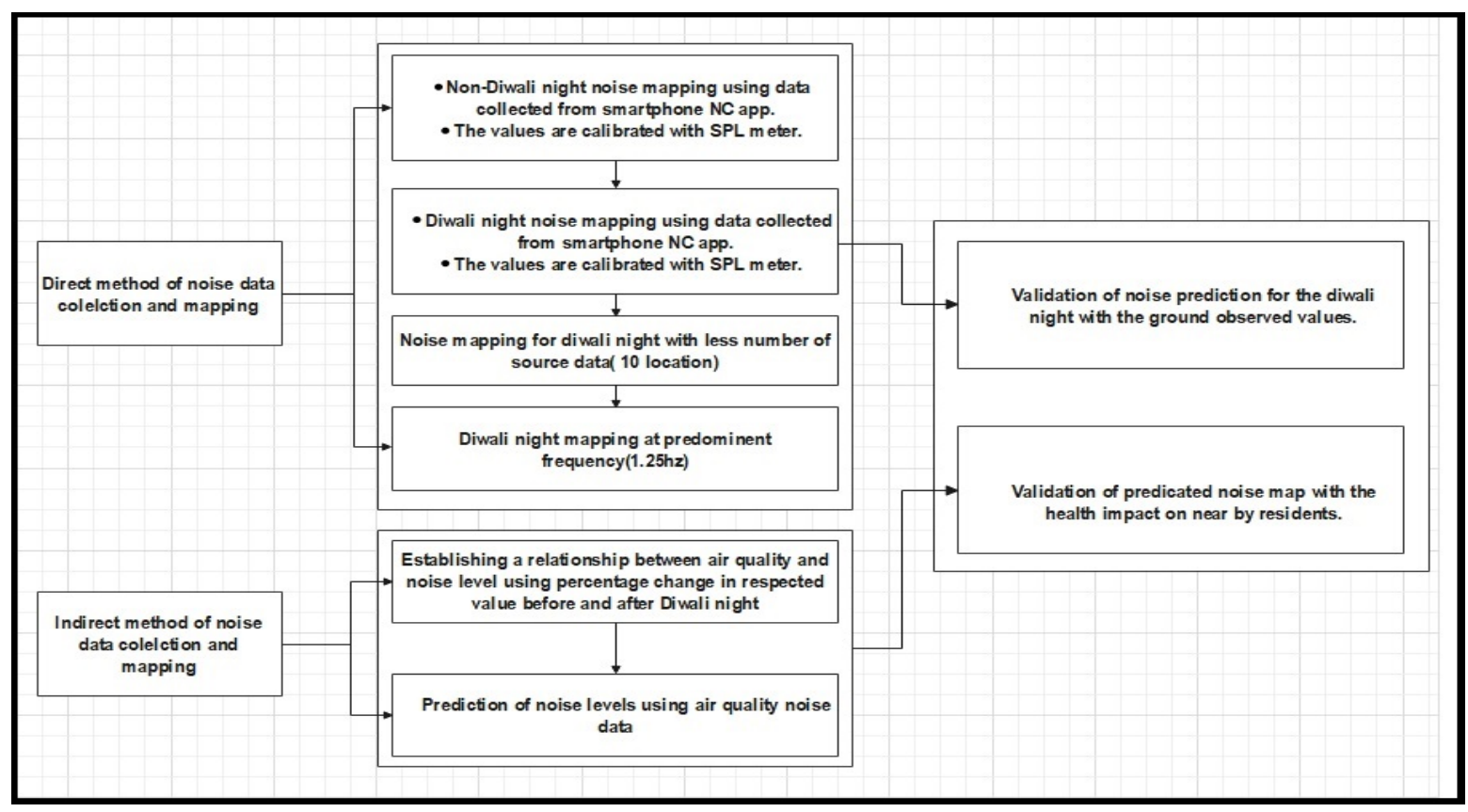

Figure 4. The flowchart shows the research that has been performed to get the result and also the validation.

\subsection{Calibration of Smartphone NC App with Standard SPL Meter}

The calibration was done in the anechoic chamber where the Smartphone NC app and SPL meter were kept $1 \mathrm{~m}$ away from the source point. The different tonal sounds were played to record the data. The value variation in the data was recorded by the Smartphone NC app with respect to the SPL meter (Table 1).

Table 1. The table shows the calibration done in the anechoic chamber of the Smartphone NC app and SPL meter.

\begin{tabular}{ccccc}
\hline $\begin{array}{c}\text { Frequency } \\
\mathbf{( H z )}\end{array}$ & & Noise Meter $\mathbf{L}_{\mathbf{e q}}$ & $\begin{array}{c}\text { Noise Capture Freq } \\
\mathbf{( d B )}\end{array}$ & $\begin{array}{c}\text { Noise Meter Freq } \\
(\mathbf{d B})\end{array}$ \\
\hline 63 & $66-67$ & 68.5 & 30 & $73-75$ \\
125 & 70 & 73.2 & $50-60$ & 80.5 \\
250 & $74.9-75.1$ & 75.5 & $58-62$ & 80.2 \\
500 & 79.8 & 82.3 & 70 & 70.5 \\
1000 & $81.7-82.0$ & 85.1 & $70-75$ & 75 \\
2000 & $83.8-84.1$ & 85.2 & $68-70$ & 71 \\
4000 & $79-8$ & 78.7 & 58 & 71 \\
10,000 & $78-80$ & 79.9 & $60-61$ & 58 \\
\hline
\end{tabular}

\subsection{Direct Method of Noise Data Collection Using a Crowd-Sourced Technique}

\subsubsection{Non-Diwali Night Noise Map of Haniman Chauraha (Residential Area)}

The noise map non-Diwali night of Haniman Crossing (Figure 5) over the GIS platform. The data collection was conducted for $10 \mathrm{~min}$ at each location and the remaining points are predicted using a noise model (interpolation-cum-modeling). The noise data was collected using the Smartphone NC app. Recorded values are calibrated with a standard SPL meter before mapping. Different noise levels are shown in the legend. There were 20 source points and 150 receiver points (away from the source), which were predicted through the 
noise model. The yellow patch in the map depicts the instantaneous mapping, where the receiver points are away from the source (road points). These points are on the lower side (with lesser values) showing only the background noise.

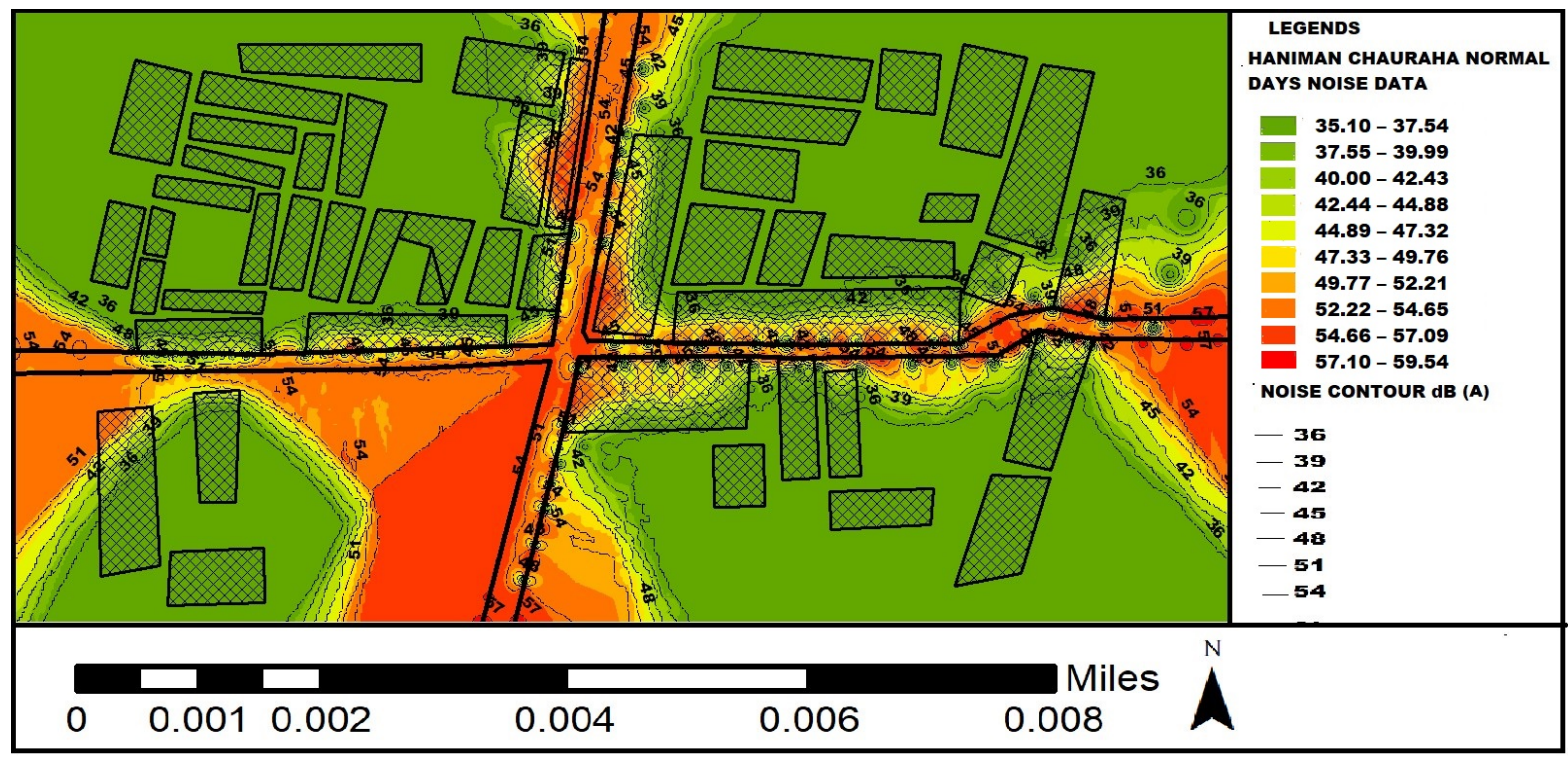

Figure 5. This is the noise map in $\mathrm{dB}(\mathrm{A})$ for Haniman Crossing for Non-Diwali night averaged for $10 \mathrm{~min}$.

\subsubsection{Diwali Night Noise Map of Haniman Crossing (Residential Area)}

This was the SNSE mapping event where the noise data collection was being performed for $10 \mathrm{~s}$ using the Smartphone NC app whose values were already calibrated with a standard SPL meter (Figure 6a,b). An instantaneous noise map was developed using a Smartphone NC app, calibrated with a standard SPL meter, and mapped over the GIS platform with 40 source points (Figure 6a). The figure shows the noise map of Diwali night for Haniman Crossing when firecrackers were bursting at 10 source points. Ten source points were given random locations in four instants while mapping. Here in this, the noise data was crowd-sourced with the Smartphone NC app calibrated with a standard SPL meter. In order to showcase the comparison between the noise values on normal days and on the festival, a map is shown (Figure 7).

To showcase the variational change in the values of the receiver points concerning the firecracker's location. The authors considered four different instances showcasing the change in the values of 50 receiver points at each instance. The difference is shown in Table 2. showing the value change from the base map with all 40 source points, that is, firecrackers are fired at the same instance. The RMSE error for four instances is also there.

Here in the above table D1, D2, D3, D4 are the differences in the values predicted for the observed 50 test points. The average RMSE was calculated for the same 50 test points for all four instants. The table showcases Diwali night for Haniman Crossing when firecrackers are bursting at 10 source points. Ten source points were given at random locations in four instants while mapping. Here in this, the noise data was crowd-sourced with the Smartphone NC app calibrated with a standard SPL meter.

- Computing out the predominant frequency in the crowd-sourced noise data collection

The authors used artificial intelligence to compute the frequency and to know the predominant frequency responsible for noise at the time of the firecracker explosion on Diwali night. Here in the study, the finding of frequency came out to be $1.25 \mathrm{KHz}$ for mid-band frequency distribution as shown in Figure 8. An instantaneous noise map was developed. using Smartphone NC app, calibrated with standard SPL meter and 
mapped over GIS platform at a predominant frequency of $1.25 \mathrm{KHz}$ using the crowdsourced technique.

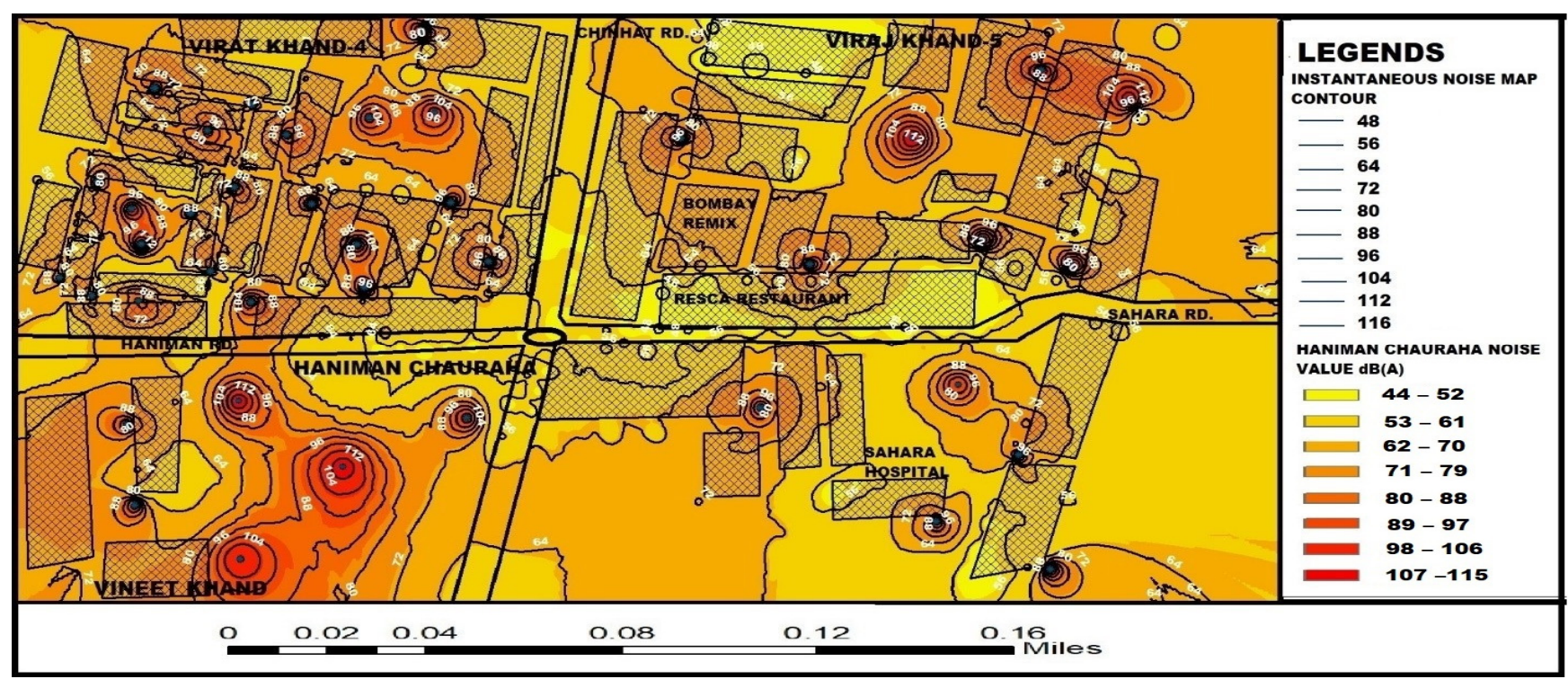

(a)
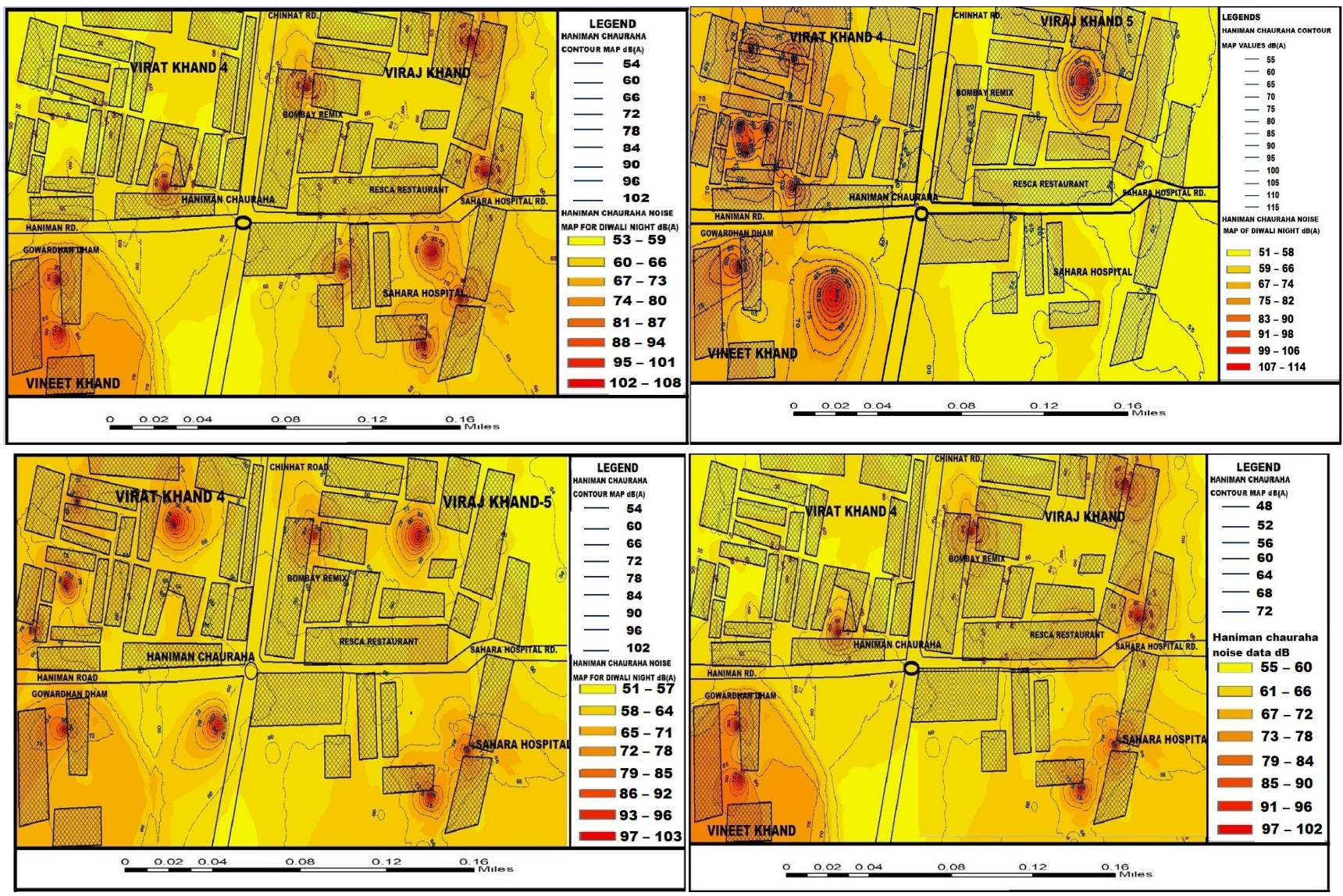

(b)

Figure 6. (a) This is the noise map of Diwali night for Haniman Crossing when firecrackers are bursting at 40 source points. (b) This is the noise map of Diwali night for Haniman Crossing when firecrackers are bursting at 10 source points at random locations in four instances. 


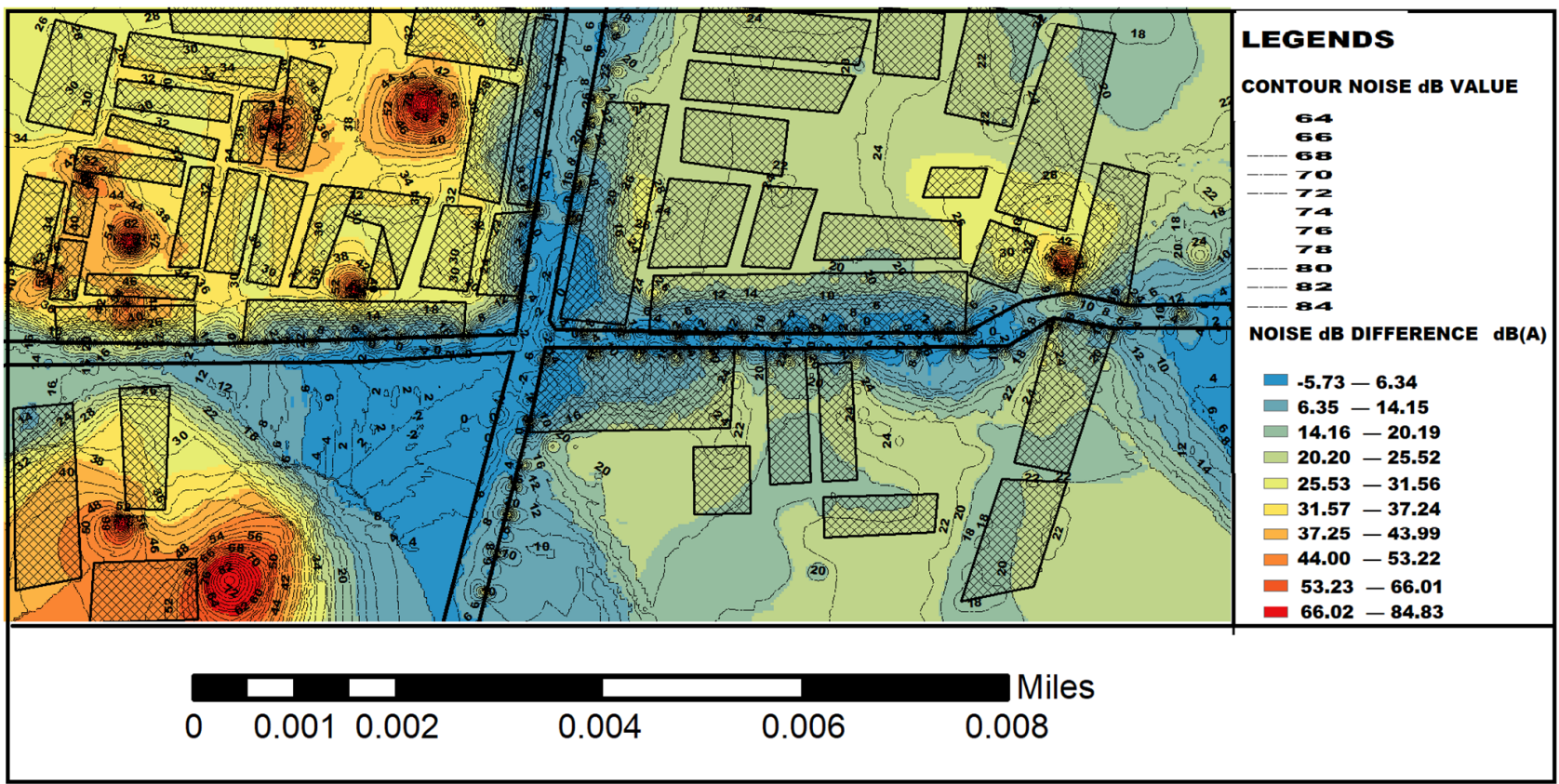

Figure 7. This is the comparison of the maps on the day of the festival and on the normal days.

Table 2. The table shows the RMSE error of 4 different slots of firecrackers being fired at 50 unknown points with 10 source points at a time.

\begin{tabular}{cccccccc}
\hline Serial No. & Point Number & X (Long) & Y (LAT) & D1 & D2 & D3 & D4 \\
\hline 1 & B 51 & 81.016902 & 26.85218 & 0.194693 & 0.076912 & 0.002106 & 0.002269 \\
2 & B 52 & 81.01699 & 26.85218 & 1.474535 & -0.50907 & 0.03238 & 0.171401 \\
3 & B 53 & 81.017053 & 26.85218 & 2.892136 & -0.39103 & -0.04987 & 0.341101 \\
4 & B 54 & 81.017098 & 26.85218 & 3.513465 & 0.147266 & -5.25202 & -4.54432 \\
5 & B 55 & 81.017145 & 26.85218 & 3.343088 & 1.187223 & -5.07267 & -4.21951 \\
& & & & 2.815043 & 2.951495 & 3.616027 & 4.030257 \\
\hline
\end{tabular}

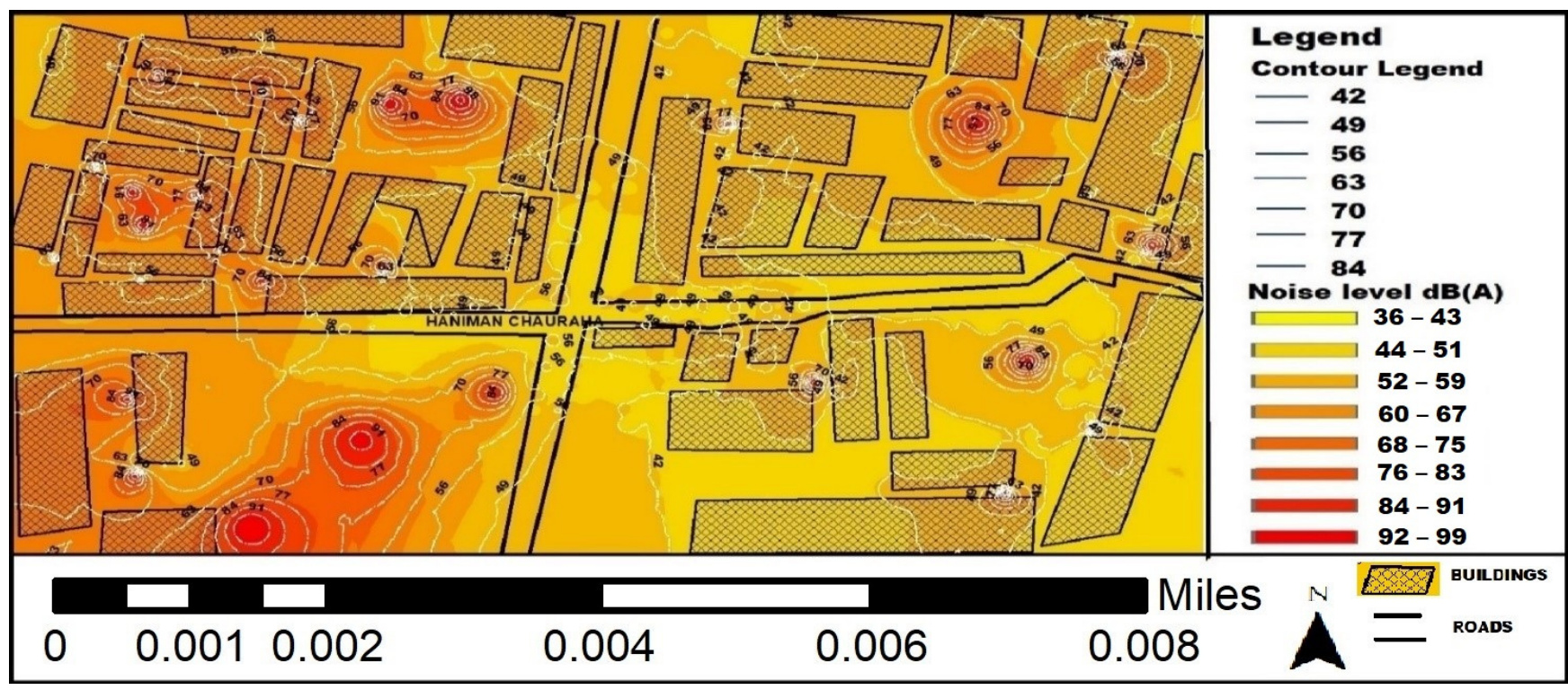

Figure 8. This is the noise map of Diwali night for Haniman Crossing when firecrackers are bursting at 40 source points. A noise map at the predominate frequency of $1.25 \mathrm{~Hz}$ is presented here. 


\subsection{Indirect Method of Noise Mapping for SNSE}

Authors established a relationship between change in air quality and change in noise levels for SNSE. With the use of the data from the IITR report (open sourced) the air quality variation due to the SNSE and change is noise pollution. Also for the validation of the data, the author also physically monitored the noise data in the city of Lucknow.

- Prediction of noise levels using air quality noise data

The relationship was established using the linear regression method where the combination of 84 equations was made with 8 trained locations data and 1 testing location point. The equation with the least RMS value was considered and the results are validated by collecting the data noise for non-Diwali nights and Diwali nights. Also, the air quality data was validated by keeping in view the IITR Lucknow data shown in (Figure 9a,b).

The variation in the air pollutant values was taken into account from the open-sourced CPCB Lucknow database. The average 10-day variation in the values of these pollutants was compared to the data recorded for Diwali night (Table 3) From the table, authors can easily predict out that there has been a substantial increase in these pollutant values which is merely due to the firecrackers being fired. The values of the pollutant matter increase from non-Diwali night to Diwali night. This least square regression technique is used to establish the relation between the percentage change in noise value and the pollutant matters especially $\mathrm{PM}_{2.5}, \mathrm{NO}_{\mathrm{x}}$, and $\mathrm{SO}_{\mathrm{x}}$ (Table 4).

From the matrix method discussed in the methodology section, $\mathrm{a}=0.01875, \mathrm{~b}=-0.07112$, $\mathrm{c}=0.4707$.

When applying these at the testing point (10 points) the RMSE error is 0.546.

$$
\mathrm{dB}=0.0185 \mathrm{x}-0.07112 \mathrm{y}+0.4707 \mathrm{z}
$$

Prediction of Noise Map from the Indirect Noise Data Collection

The elliptical drawn over the map shows the value over the whole of the shaded region to be $80 \mathrm{~dB}(\mathrm{~A})$, which comes out from the change in percentage of $\mathrm{dB}$ value from non-Diwali night to Diwali night for Haniman Crossing (Figure 10). This testing was done for 50 points with both source and receiver points (away from the source), which comes out to be $\pm 6.2 \mathrm{~dB}$ (Table 5). A single noise level (of $80 \mathrm{~dB}(\mathrm{~A})$ is predicted and showed as violet oval overlapping on the crowd-sourced noise data collected during Diwali night. The above map compares the deviation between air quality-based predicted noise map with crowd source-based noise map using collected data from the ground.

Table 3. The table shows the percentage change in the $\mathrm{dB}$ value with the change in the air quality parameters.

\begin{tabular}{cccc}
\hline Date & $\mathbf{P M}_{\mathbf{2 . 5}}$ & $\mathbf{N O}_{\mathbf{x}}$ & $\mathbf{S O}_{\mathbf{x}}$ \\
\hline 10 day before Diwali & 105 & 27.8 & 17.02 \\
\hline 9 days before Diwali & 120 & 20.2 & 10.48 \\
\hline 8 day before Diwali & 113.5 & 20.35 & 8.88 \\
\hline 7 day before Diwali & 140.5 & 32.95 & 14.55 \\
\hline 6 day before diwali & 100.75 & 26.47 & 13.4 \\
\hline 5 day before Diwali & 80.75 & 45.73 & 17.25 \\
\hline 4 day before Diwali & 80.5 & 30.85 & 10.34 \\
\hline 3 day before Diwali & 56 & 28.9 & 18.9 \\
\hline 2 day before Diwali & 49.75 & 18.23 & 11.7 \\
\hline 1 day before Diwali & 52 & 39.45 & 21.48 \\
\hline Average of 10 days & 89.875 & 29.093 & 14.4 \\
\hline Diwali night (27 October 2019) & 212.25 & 35.88 & 77.74 \\
\hline
\end{tabular}



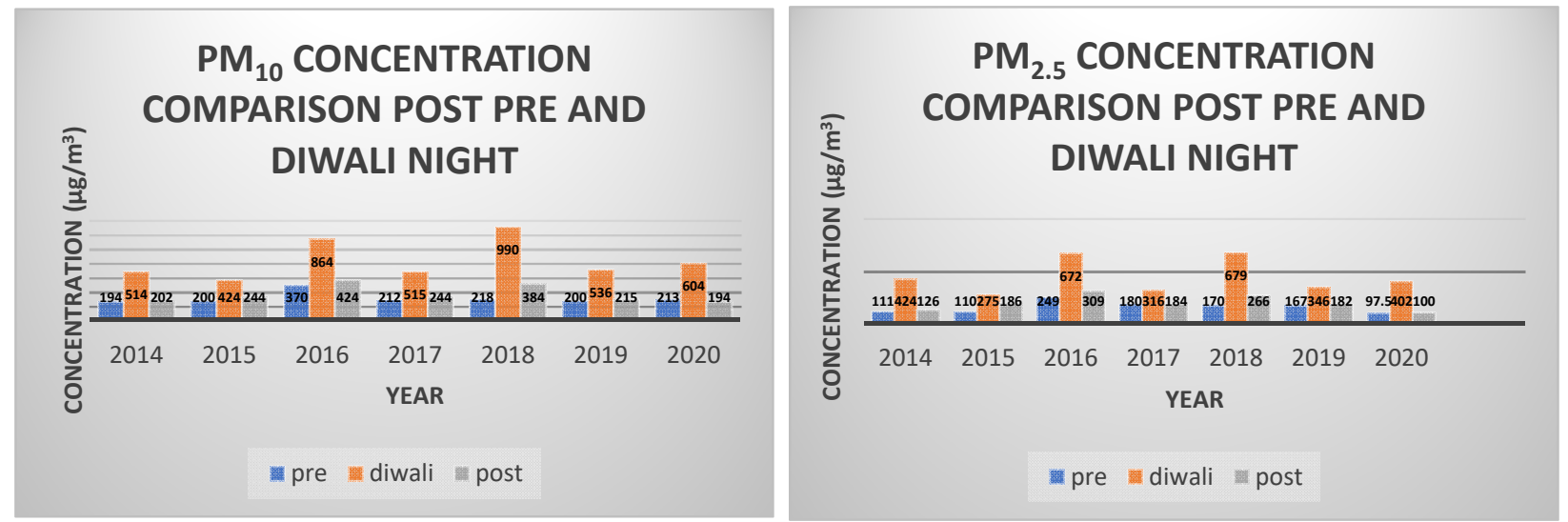

(a)
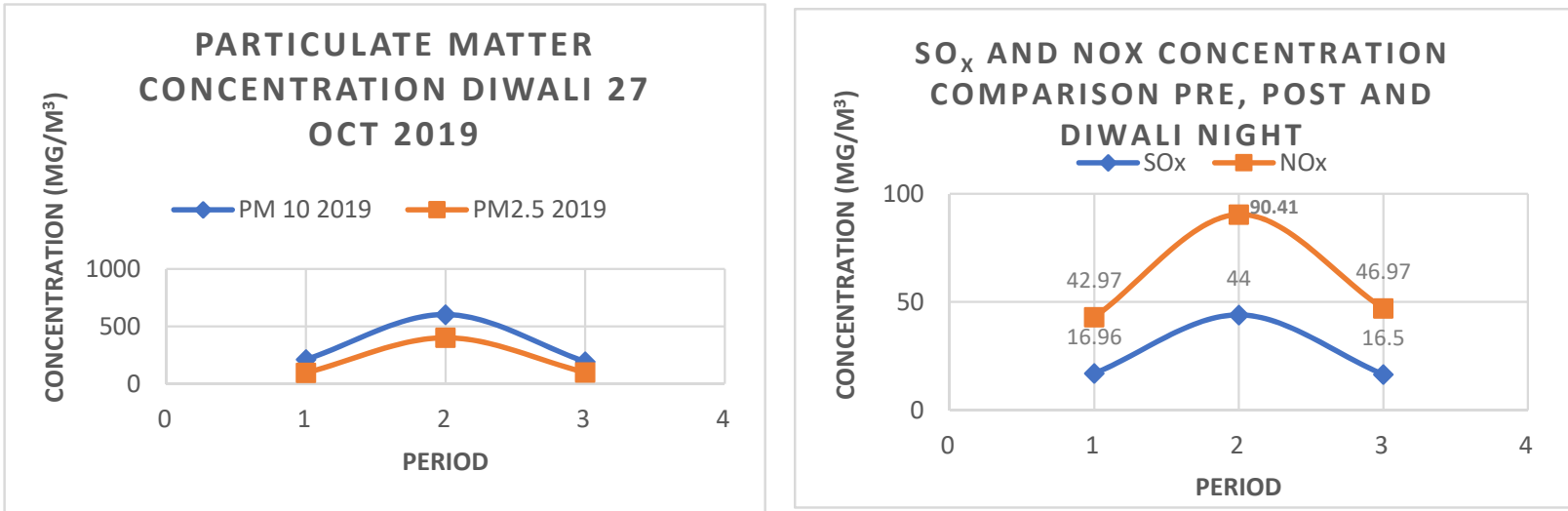

(b)

Figure 9. (a) This shows the variation in the $\mathrm{PM}_{10}$ and $\mathrm{PM}_{2.5}$ concentration on Diwali for 7 years for pre-post and Diwali night. (b) This shows the variation in the $\mathrm{PM}_{10}, \mathrm{PM}_{2.5}, \mathrm{NO}_{\mathrm{x}}$, and $\mathrm{SO}_{\mathrm{x}}$ concentration on Diwali for the year 2019 for pre-post and Diwali night.

Table 4. The table shows the variation in the percentage change in the $\mathrm{dB}$ value by putting the air pollutant values in the established equation.

\begin{tabular}{cccc}
\hline Description & $\mathbf{0 . 0 1 8 7 5 x}$ & $\mathbf{0 . 0 7 1 1 2 y}$ & $\mathbf{0 . 4 7 0 7 z}$ \\
\hline Percentage change calculated of air pollutant & 1.06 & 1.34 & 38.31 \\
Percentage change in dB value & $\mathrm{dB}=0.0185 \mathrm{x}-0.07112 \mathrm{y}+0.4707 \mathrm{z}$ & & $38.03 \%$ \\
\hline
\end{tabular}

Table 5. The table shows the percentage change in the pollutants like PM2.5, NOx, and SOx and the $\mathrm{dB}$ value for 9 places of Lucknow for the year 2019 on Diwali.

\begin{tabular}{cccccc}
\hline S.No. & Place & $\mathbf{P M}_{\mathbf{2 . 5}}(\mathbf{x})$ & $\mathbf{N O}_{\mathbf{x}}(\mathbf{y})$ & $\mathbf{S O}_{\mathbf{x}} \mathbf{( z )}$ & $\begin{array}{c}\text { dB Observed } \\
\text { (\% Change) }\end{array}$ \\
\hline 1 & Charbagh & 145.35 & 51.88 & 60.74 & 32.75 \\
\hline 2 & Aliganj & 46.22 & 45.64 & 40.6 & 11.82 \\
\hline 3 & Vikas nagar & 126.47 & 25.47 & 46.84 & 19.44 \\
\hline 4 & Aminabad & 210.92 & 31.62 & 38.77 & 17.83 \\
\hline 5 & Gomtinagar & 277.03 & 39.58 & 43.09 & 30.7 \\
\hline 6 & Amausi & 65.51 & 52.79 & 44.63 & 17.2 \\
\hline 7 & Rajajipuram & 267.5 & 43.6 & 52.6 & 24.5 \\
\hline 8 & Hazratganj & 55.6 & 37.6 & 42 & 27.6 \\
\hline
\end{tabular}




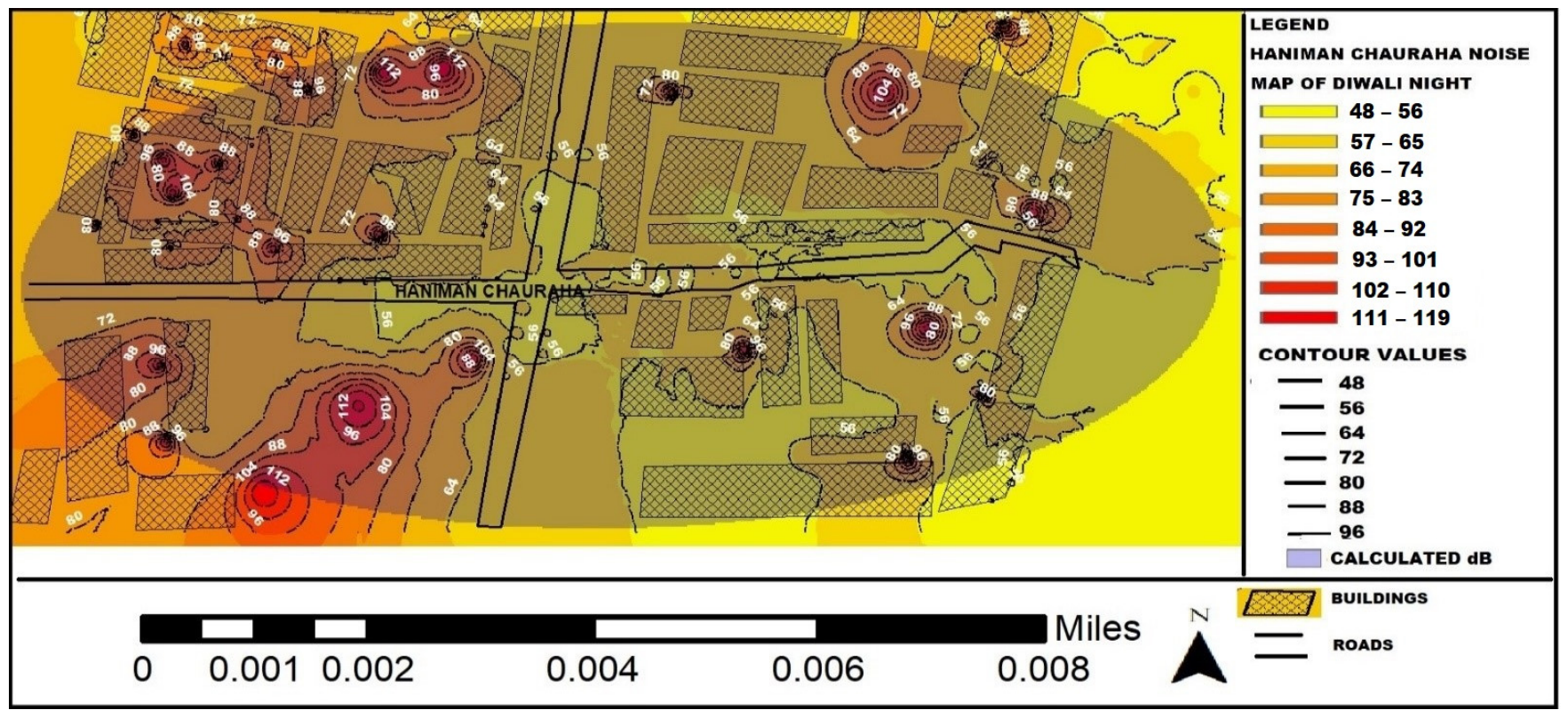

Figure 10. Noise map of Haniman Crossing at Diwali Night predicted using noise data generated indirectly using change in air quality data.

\section{Validation}

Validation was performed both for the direct method of data collection (crows-sourced data) and also for the indirect method of data collection (air quality variation). The following tables show the validation:

- Validation of noise prediction for the Diwali night with the ground observed values.

- Validation of predicted noise map with the health impact on nearby residents.

In Table 6, a total of 810 points out of which 730 are training points and 80 are testing points. In this, some of the points are considered close to the source and some away from the source (receiver). The predicted value was higher than the observed value, so the prediction is over-predicting. Usually, points close to the source and away from the source are considered to verify the results. The error variation in the values comes out to be $\pm 4.5 \mathrm{~dB}$.

Table 6. The table shows the Diwali night observed and the predicted value of Haniman Chauraha, where 81 points are been compared over the map also in the table and their average difference is stimulated out.

\begin{tabular}{|c|c|c|c|c|c|c|}
\hline S.No. & Point & $x_{-}$ & $\mathbf{y}_{-}$ & Predicted Value dB (A) & Observed Value & Difference \\
\hline 1 & b 10 & 81.017161 & 26.851859 & 82.2765503 & 76.48827 & 5.78 \\
\hline 2 & b 11 & 81.017247 & 26.851861 & 83.0420151 & 74.57508 & 8.46 \\
\hline 3 & b 12 & 81.017347 & 26.85187 & 82.1891174 & 73.17945 & 9.00 \\
\hline 4 & b 13 & 81.01746 & 26.851877 & 79.0921326 & 72.08816 & 7.00 \\
\hline 51 & b 99 & 81.016533 & 26.852102 & 72.7562866 & 69.91484 & 2.84 \\
\hline 52 & b 100 & 81.016541 & 26.852138 & 74.3925095 & 75.00443 & -0.61 \\
\hline \multirow[t]{2}{*}{53} & b 101 & 81.016344 & 26.852535 & 73.0090866 & 73.87476 & -0.86 \\
\hline & & & & & Average & \pm 4.5 \\
\hline
\end{tabular}

B 10,11,12,13 .. 99, 100, 101 are the building points. $X_{-}$and $Y_{-}$are the coordinates of a point in degree decimal.

In Table 7 total of 810 points out of which 760 are training points and 50 are testing points. In this, some of the points are considered close to the source and some away 
from the source (receiver). Noise map of Haniman Crossing at Diwali Night predicted using noise data generated indirectly using change in air quality data. A single noise level (of $80 \mathrm{~dB}(\mathrm{~A}$ ) is predicted during Diwali night. The below table compares the deviation between air quality-based predicted noise map with crowd source-based noise map using collected data from the ground. The error variation in the values comes out to be $\pm 6.2 \mathrm{~dB}$.

Table 7. The table shows the difference in Smartphone NC app-based ground collected noise levels and air quality based indirect noise map determined using the regression equation.

\begin{tabular}{ccccccc}
\hline S.No. & Point & X (Long) & Y (Lat) & Source PT (D) & Calculated Value (ID) & Difference \\
\hline 1 & B 274 & 81.017585 & 26.85412 & 75.64 & 80 & -4.35 \\
\hline 2 & B 275 & 81.017697 & 26.85414 & 76.98 & 80 & -3.01 \\
\hline 3 & B 276 & 81.017853 & 26.85407 & 80.61 & 80 & 0.61 \\
\hline 47 & S 1 & 81.016831 & 26.85057 & 117.00 & 80 & 37 \\
\hline 48 & S 15 & 81.024872 & 26.84954 & 118.00 & 80 & 38 \\
\hline 49 & S 16 & 81.025694 & 26.85025 & 114.00 & 80 & 34 \\
\hline 50 & S 17 & 81.024632 & 26.85361 & 114.00 & 80 & 34 \\
\hline & & Average & & \pm 6.2 \\
\hline
\end{tabular}

B 274, 275, 276 are the building points. S1, 15, 16,17 are the source points. D is the direct source noise value. ID is the indirect source noise value.

The noise data variation in terms of maximum and minimum values recorded for three locations based on high, medium, and low collected using the crowd-sourced technique. The variation average change $10 \mathrm{~min}$ monitoring for a non-Diwali night and Diwali night for 3 locations (Table 8). The SNSE was shown in terms of 10-s average data collection. This is to verify the result of the variation in minimum and maximum values recorded.

Table 8. The table shows the comparison of non-Diwali night noise data of three locations with the Diwali night noise data value collected using the crowd-sourced technique.

\begin{tabular}{|c|c|c|c|c|c|c|}
\hline \multirow[b]{2}{*}{ S.No. } & \multirow{2}{*}{\multicolumn{2}{|c|}{ Location }} & \multicolumn{2}{|c|}{ Non-Diwali } & \multicolumn{2}{|c|}{ Diwali } \\
\hline & & & $\begin{array}{l}\text { Maximum } \\
\text { Noise Value }\end{array}$ & $\begin{array}{l}\text { Minimum } \\
\text { Noise Value }\end{array}$ & $\begin{array}{l}\text { Maximum } \\
\text { Noise Value }\end{array}$ & $\begin{array}{l}\text { Minimum } \\
\text { Noise Value }\end{array}$ \\
\hline \multirow{2}{*}{1} & \multirow{2}{*}{ Haniman chauraha } & Average data & 60.11 & 35 & 97.6 & 47.06 \\
\hline & & Instantaneous data & 74.5 & 43.6 & 107.2 & 54.06 \\
\hline \multirow{2}{*}{2} & \multirow{2}{*}{ Polytechnic chauraha } & Average data & 74.59 & 35 & 99.5 & 42.45 \\
\hline & & Instantaneous data & 82.4 & 51.2 & 104.6 & 53.28 \\
\hline \multirow{2}{*}{3} & \multirow{2}{*}{ Hazartganj chauraha } & Average data & 67.89 & 35 & 101.4 & 46.85 \\
\hline & & Instantaneous data & 79.46 & 48.6 & 108.4 & 55.8 \\
\hline
\end{tabular}

- Health assessment of Haniman chauraha

As per the health assessment shown in Table 9. based on the age distribution to give an aspect that which age is more affected by the effect of noise pollution on SNSE. People residing in the closed area or dense pockets were primarily more prone to noise pollution as compared to people living in the open vicinity. Table 10 shows the survey result of a number of respondents of different ages to different diseases at the time of Diwali night at Haniman Chauraha in Lucknow of 270 People were surveyed and Figure 11 shows the bar graph of the survey result. In Figure 12, the map shows the noise map of Haniman chauraha with 40 source points with different colors of patches showing the level of noise impacts where the green indicates lowest and red the highest health impacts. 
Table 9. Age distribution in the percentage of people living in the Haniman Chauraha mapping area.

\begin{tabular}{ccc}
\hline People & Percentage & Numbers \\
\hline$<10$ & $5 \%$ & 88 \\
\hline 10 TO 18 & $30 \%$ & 525 \\
\hline $18-30$ & $15 \%$ & 262 \\
\hline $30-60$ & $30 \%$ & 525 \\
\hline $60>$ & $20 \%$ & 350 \\
\hline
\end{tabular}

Table 10. The table shows the survey result of a number of respondents of different ages to different diseases at the time of Diwali night at Haniman Chauraha in Lucknow of 270 People.

\begin{tabular}{|c|c|c|c|c|c|c|c|c|c|c|c|c|c|c|c|c|c|c|c|}
\hline \multirow{2}{*}{ Age Group } & \multicolumn{3}{|c|}{ Tinnitus } & \multicolumn{3}{|c|}{ Anxiety } & \multicolumn{3}{|c|}{ High bp } & \multicolumn{3}{|c|}{ Cardio Vascular Disease } & \multicolumn{3}{|c|}{ Hyper-Tension } & \multicolumn{3}{|c|}{ Sleep Disturbance } & \multirow[t]{2}{*}{ Total } \\
\hline & $T$ & $\mathrm{O}$ & $\mathrm{C}$ & $\mathrm{T}$ & $\mathrm{O}$ & $\mathrm{C}$ & $\mathbf{T}$ & $\mathbf{O}$ & $\mathrm{C}$ & $\mathrm{T}$ & $\mathbf{O}$ & $\mathrm{C}$ & $\mathrm{T}$ & $\mathbf{O}$ & $\mathrm{C}$ & $\mathbf{T}$ & $\mathbf{O}$ & $\mathrm{C}$ & \\
\hline$<10$ & 4 & 1 & 3 & 1 & 1 & 0 & 0 & 0 & 0 & 3 & 1 & 2 & 1 & 0 & 1 & 6 & 2 & 4 & 15 \\
\hline 10 to 18 & 12 & 4 & 8 & 5 & 2 & 3 & 0 & 0 & 0 & 2 & 1 & 1 & 9 & 3 & 6 & 10 & 4 & 6 & 38 \\
\hline $18-30$ & 6 & 3 & 3 & 8 & 4 & 4 & 5 & 2 & 3 & 6 & 2 & 4 & 12 & 5 & 7 & 6 & 2 & 4 & 43 \\
\hline $30-60$ & 10 & 6 & 4 & 15 & 7 & 8 & 16 & 7 & 9 & 2 & 0 & 2 & 14 & 6 & 8 & 20 & 9 & 11 & 77 \\
\hline $60>$ & 20 & 13 & 7 & 18 & 8 & 10 & 19 & 9 & 10 & 3 & 1 & 2 & 21 & 7 & 14 & 16 & 7 & 8 & 97 \\
\hline Total & 52 & & & 47 & & & 40 & & & 16 & & & 57 & & & 58 & & & 270 \\
\hline
\end{tabular}

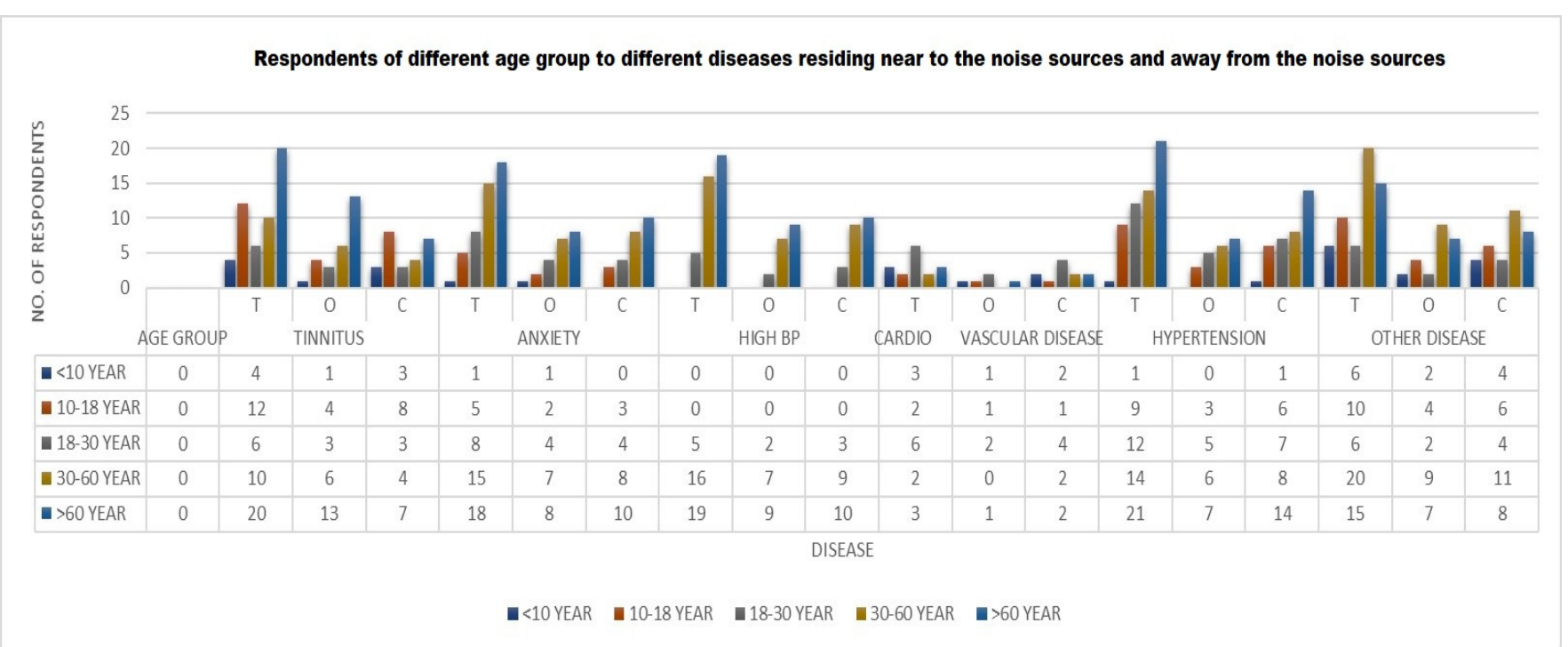

Figure 11. The bar graph is showing the noise survey result of Haniman Chauraha depicting the respondent of different ages to different diseases residing near to the noise sources and away from noise sources. 


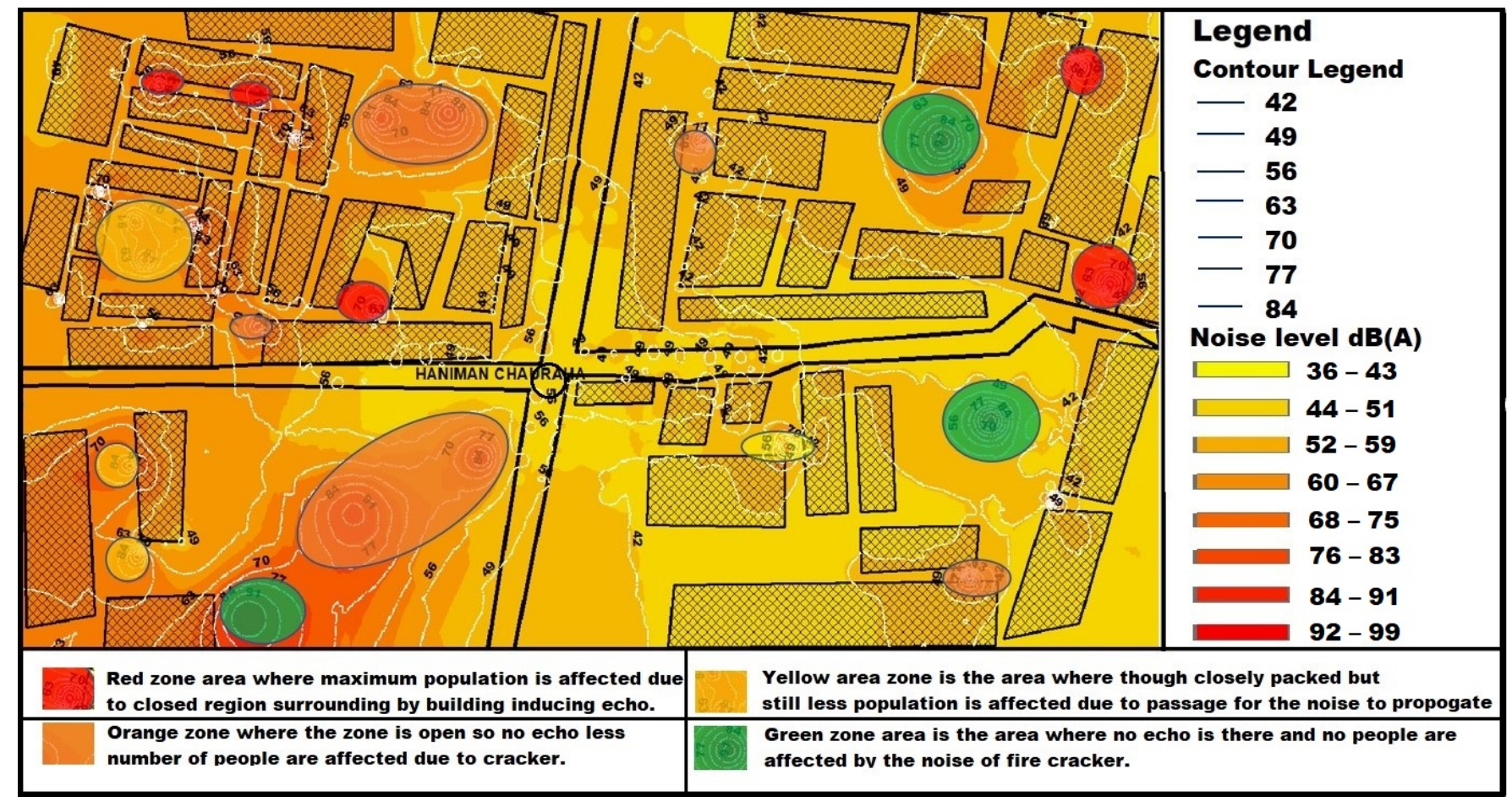

Figure 12. This is the noise map of Haniman chauraha with 40 source points with different color of patches showing the level of noise impacts where the green indicates lowest and red the highest health impacts.

\section{Conclusions}

Mapping of noise levels for short-span Noise Sensitive Events-SNSE, for example, Diwali Night is challenging. The transient nature of the event is characterized by wide fluctuation in noise levels within a short period of time. Prediction of short-span noise events which are instantaneous in nature is extremely difficult. It suffers inaccuracy. The authors attempted to predict noise levels using crowdsource technique for the SNSE event Diwali. This technique gave an accuracy of $\pm 4.5 \mathrm{~dB}(\mathrm{~A})$. The technique showcased how to generate a noise map for the transient noise-sensitive event using crowdsource technique of noise data collection. It requires the collection of noise data from the ground close to the noise source and away points. Once noise data are collected these are calibrated before mapping over the web interface. Collection of noise data of a large number of points, 810 total with 760 training and 50 testing points play important role in terms of training of prediction model and its testing. Better knowledge about land use and land cover helps in deciding about source points and away points and choosing appropriate sampling time. Authors developed a smart, easy, and low-cost methodology for collecting and mapping of noise data. The authors have also mapped the data for Diwali night and have successfully compared it with the data collected for non-Diwali nights. It indicated a significant change in noise levels at different pockets of the city compared with non-Diwali nights. Collection of noise data even with noise capturing App is difficult as people remain busy with celebration. Thus, an indirect technique of noise data generation is attempted. A relationship is being established between change in air quality parameters on Diwali Nights compared with non-Diwali nights along with the change in noise levels in similar periods recorded through indirect measurements. The authors established a relationship to predict probable percentage change in noise levels in an area due to changes in air pollution levels due to Diwali. The authors successfully used this technique to predict the noise levels of the project site during Diwali night without using any direct data of noise levels. It was found to be accurate within $\pm 6.2 \mathrm{~dB}(\mathrm{~A})$, when compared with ground data of test points, which is a reasonable prediction for any short-span fluctuating event. The predictions were 
verified with a health survey for the area too. The survey was conducted for 270 people on the basis of various diseases suffered by the people. The results of the health survey were corroborated with Diwali night's noise map was very significant. People were more prominent to the effect of Hypertension with a total of 57, on the other hand for anxiety it comes out to be 47 , and sleep disturbance was found to be common amongst the residents of the nearby area. Further, the noise source locations restricted by walls or obstructions in their vicinity indicated very high noise levels and alarming health hazards compared to sources at open locations.

\begin{abstract}
Author Contributions: Conceptualization, Shruti Bharadwaj; Data curation, Shruti Bharadwaj, Md Iltaf Zafar and Vanshu Mahajan; Formal analysis, Shruti Bharadwaj; Funding acquisition, Susham Biswas; Investigation, Anubhava Srivastava; Methodology, Rakesh Dubey and Shruti Bharadwaj; Project administration, Rakesh Dubey; Resources, Md Iltaf Zafar; Software, Rakesh Dubey, Vanshu Mahajan and Susham Biswas; Supervision, Susham Biswas; Validation, Rakesh Dubey, Vanshu Mahajan and Anubhava Srivastava; Writing—original draft, Rakesh Dubey; Writing_review \& editing, Shruti Bharadwaj and Susham Biswas. All authors have read and agreed to the published version of the manuscript.
\end{abstract}

Funding: This research received no external funding.

Institutional Review Board Statement: Not applicable.

Informed Consent Statement: Not applicable.

Data Availability Statement: Not applicable.

Acknowledgments: The authors are thankful to Rajiv Gandhi Institute of Petroleum Technology, A.S.K. Sinha, for instilling a positive research environment on campus. Also, the authors are thankful to Rashid Aziz Faridi, Department of Geography at Aligarh Muslim University for his support in writing this article.

Conflicts of Interest: The authors declare no conflict of interest.

\title{
References
}

1. Bharadwaj, S.; Dubey, R.; Zafar, M.I.; Srivastava, A.; Bhushan Sharma, V.; Biswas, S. Determination of Optimal Location for Setting Up Cell Phone Tower in City Environment Using Lidar Data. ISPRS—Int. Arch. Photogramm. Remote Sens. Spat. Inf. Sci. 2020, 43, 647-654. [CrossRef]

2. Rossi, L.; Prato, A.; Lesina, L.; Schiavi, A. Effects of low-frequency noise on human cognitive performances in laboratory. Build. Acoust. 2018, 25, 17-33. [CrossRef]

3. Hume, K.I.; Brink, M.; Basner, M. Effects of environmental noise on sleep. Noise Health 2012, 14, 297-302. [CrossRef] [PubMed]

4. Miedema, H.M.E.; Oudshoorn, C.G.M. Annoyance from transportation noise: Relationships with exposure metrics DNL and DENL and their confidence intervals. Environ. Health Perspect. 2001, 109, 409-416. [CrossRef] [PubMed]

5. Dratva, J.; Phuleria, H.C.; Foraster, M.; Gaspoz, J.M.; Keidel, D.; Künzli, N.; Sally Liu, L.J; Pons, M.; Zemp, E.; Gerbase, M.W.; et al. Transportation noise and blood pressure in a population-based sample of adults. Environ. Health Perspect. 2012, 120, 50-55. [CrossRef] [PubMed]

6. Babisch, W.; Beule, B.; Schust, M.; Kersten, N.; Ising, H. Traffic noise and risk of myocardial infarction. Epidemiology 2005, 16, 33-40. [CrossRef] [PubMed]

7. Petri, D.; Licitra, G.; Vigotti, M.A.; Fredianelli, L. Effects of Exposure to Road, Railway, Airport and Recreational Noise on Blood Pressure and Hypertension. Int. J. Environ. Res. Public Health 2021, 18, 9145. [CrossRef] [PubMed]

8. Halperin, D. Environmental noise and sleep disturbances: A threat to health? Sleep Sci. 2014, 7, 209-212. [CrossRef] [PubMed]

9. Liu, X.; Zhang, Z.; Peterson, J.; Chandra, S. Large Area DEM Generation Using Airborne LiDAR Data and Quality Control. Int. J. Geogr. Inf. Sci. 2008, 2, 79-85.

10. Graziuso, G.; Mancini, S.; Francavilla, A.B.; Grimaldi, M.; Guarnaccia, C. Geo-Crowdsourced Sound Level Data in Support of the Community Facilities Planning. A Methodological Proposal. Sustainability 2021, 13, 5486. [CrossRef]

11. Zafar, M.I.; Bharadwaj, S.; Dubey, R.; Biswas, S. Different Scales of Urban Traffic Noise Prediction. Int. Arch. Photogramm. Remote Sens. Spat. Inf. Sci.-ISPRS Arch. 2020, 43, 1181-1188. [CrossRef]

12. Madariaga, D.; Madariaga, J.; Bustos-jiménez, J. Improving Signal-Strength Aggregation for Mobile Crowdsourcing Scenarios. Sensors 2021, 21, 1084. [CrossRef] [PubMed]

13. Picaut, J.; Fortin, N.; Bocher, E.; Petit, G.; Aumond, P.; Guillaume, G. An open-science crowdsourcing approach for producing community noise maps using smartphones. Build. Environ. 2019, 148, 20-33. [CrossRef] 
14. Bocher, E.; Guillaume, G.; Picaut, J.; Petit, G.; Fortin, N. Noisemodelling: An open source GIS based tool to produce environmental noise maps. ISPRS Int. J. Geo-Inf. 2019, 8, 130. [CrossRef]

15. Banerjee, D. Road traffic noise exposure and annoyance: A cross-sectional study among adult Indian population. Noise Health 2013, 15, 342-346. [CrossRef] [PubMed]

16. Akintuyi, A.; Raji, A.S.; Wunude, E. Gis-Based Assessment and Mapping of Noise Pollution in Bariga Area of Lagos State, Nigeria Gis-Based Assessment and Mapping of Noise Pollution in Bariga Area of Lagos State, Nigeria. Sokoto J. Soc. Sci. Vol. 2014, 4, 154-168.

17. Vukić, L.; Mihanović, V.; Fredianelli, L.; Plazibat, V. Seafarers' Perception and Attitudes towards Noise Emission on Board Ships. Int. J. Environ. Res. Public Health 2021, 18, 6671. [CrossRef] [PubMed]

18. Biswas, S.; Lohani, B. Development of High Resolution 3D Sound Propagation Model Using LIDAR Data and Air Photo. Int. Arch. Photogramm. 2008, XXXVII, 1735-1740.

19. Bharadwaj, S.; Dubey, R.; Biswas, S. Determination of the best location for setting up a transmission tower in the city. In Proceedings of the 2020 International Conference on Smart Innovations in Design, Environment, Management, Planning and Computing (ICSIDEMPC), Aurangabad, India, 30-31 October 2020; pp. 63-68. [CrossRef]

20. Maguire, D.J. ArcGIS: General-Purpose GIS Software. Encycl. GIS 2016, 1-8. [CrossRef]

21. Esri, A. ArcGIS Secure Mobile Implementation Patterns. 2018. Available online: https://downloads.esri.com/resources/ enterprisegis/esri\%20whitepaper\%20-\%20arcgis\%20secure\%20mobile\%20implementation\%20patterns.pdf (accessed on 23 October 2021).

22. Dubey, R.; Bharadwaj, S.; Biswas, D.S. Intelligent Noise Mapping using Smart Phone on Web platform. In Proceedings of the 2020 International Conference on Smart Innovations in Design, Environment, Management, Planning and Computing (ICSIDEMPC), Aurangabad, India, 30-31 October 2020; pp. 69-74. [CrossRef]

23. Bocher, E.; Guillaume, G.; Fortin, N.; Picaut, J.; Can, A.; Gauvreau, B. Crowdsourcing of Noise Map Pollution Using Smartphones; European NEtwork for Redistributing Geospatial Information to user Communities-Open Data; 2015. Available online: https:/ / halshs.archives-ouvertes.fr/halshs-01164870/file/CNRS_LSSR_meeting_2015.pdf (accessed on 23 October 2021).

24. Chiang, Y.-Y.; Knoblock, C.A. Extracting Road Vector Data from Raster Maps. In International Workshop on Graphics Recognition; Springer: Berlin, Heidelberg, 2009; pp. 93-105.

25. Ascari, E.; Licitra, G.; Teti, L.; Cerchiai, M. Low frequency noise impact from road traffic according to different noise prediction methods. Sci. Total Environ. 2015, 505, 658-669. [CrossRef]

26. Teti, L.; de León, G.; Del Pizzo, A.; Moro, A.; Bianco, F.; Fredianelli, L.; Licitra, G. Modelling the acoustic performance of newly laid low-noise pavements. Constr. Build. Mater. 2020, 247, 118509. [CrossRef]

27. Yerramsetti, V.S.; Sharma, A.R.; Gauravarapu Navlur, N.; Rapolu, V.; Dhulipala, N.S.K.C.; Sinha, P.R. The impact assessment of Diwali fireworks emissions on the air quality of a tropical urban site, Hyderabad, India, during three consecutive years. Environ. Monit. Assess. 2013, 185, 7309-7325. [CrossRef] [PubMed]

28. Dubey, R.; Bharadwaj, S.; Zafar, M.I.; Biswas, S. Collaborative Air Quality Mapping of Different Metropolitan Cities of India. Int. Arch. Photogramm. Remote Sens. Spat. Inf. Sci. 2021, 43, 87-94. [CrossRef]

29. Singh, A.; Pant, P.; Pope, F.D. Air quality during and after festivals: Aerosol concentrations, composition and health effects. Atmos. Res. 2019, 227, 220-232. [CrossRef]

30. Wu, Q.; Cao, J.; Zhou, C.; Huang, J.; Li, Z.; Cheng, S.M.; Cheng, J.; Pan, G. Intelligent Smoke Alarm System with Wireless Sensor Network Using ZigBee. Wirel. Commun. Mob. Comput. 2018, 7212567. [CrossRef] 